\title{
The study of down-hole hydro-cyclone efficiency in oil wells using computational fluid dynamics
}

\author{
Ahmed A. Yusuf \\ West Virginia University
}

Follow this and additional works at: https://researchrepository.wvu.edu/etd

\section{Recommended Citation}

Yusuf, Ahmed A., "The study of down-hole hydro-cyclone efficiency in oil wells using computational fluid dynamics" (2006). Graduate Theses, Dissertations, and Problem Reports. 3272.

https://researchrepository.wvu.edu/etd/3272

This Thesis is protected by copyright and/or related rights. It has been brought to you by the The Research Repository @WVU with permission from the rights-holder(s). You are free to use this Thesis in any way that is permitted by the copyright and related rights legislation that applies to your use. For other uses you must obtain permission from the rights-holder(s) directly, unless additional rights are indicated by a Creative Commons license in the record and/ or on the work itself. This Thesis has been accepted for inclusion in WVU Graduate Theses, Dissertations, and Problem Reports collection by an authorized administrator of The Research Repository @ WVU. For more information, please contact researchrepository@mail.wvu.edu. 


\title{
THE STUDY OF DOWN-HOLE HYDRO-CYCLONE EFFICIENCY IN OIL WELLS USING COMPUTATIONAL FLUID DYNAMICS
}

\author{
AHMED A. YUSUF \\ A Thesis Submitted to the College of \\ Engineering and Mineral Resources \\ at West Virginia University \\ in partial fulfillment of the requirements \\ for the degree of \\ Master of Science \\ in \\ Petroleum and Natural Gas Engineering
}

Dr. H. Ilkin Bilgesu, Ph.D., Chairperson

Prof. Samuel Ameri, M.S.

Dr. Daniel E. Della-Giustina, Ph.D.

Department of Petroleum and Natural Gas Engineering Morgantown, West Virginia

2006

Keywords: Petroleum and Natural Gas Engineering, Hydro-cyclone, Computational Fluid Dynamic (CFD), Water-Oil Separation 


\title{
ABSTRACT \\ THE STUDY OF DOWN-HOLE HYDRO-CYCLONE EFFICIENCY IN OIL WELLS USING COMPUTATIONAL FLUID DYNAMICS
}

\begin{abstract}
AHMED A. YUSUF
Water is by far the largest waste stream associated with oil and gas production and it is unimaginable to find an oil reservoir absolutely free from connate water. Water management has become an important issue of hydrocarbon production, since the produced water increases as the field grows older and the cost of water handling, such as separation, treatment and repair is dramatically increasing. Down-Hole Separation (DOWS) and re-injection results in the production of oil to the surface, while portions of water are injected to the underground formation without ever being lifted to the surface
\end{abstract}

DOWS depends on geological characteristics of the producing and injection formation, down-hole conditions, well configuration and equipment, installation procedures, hydrocyclone arrangement and water disposal.

With their compact size, Liquid-Liquid Hydro-Cyclones (LLHC) can perform as an integral part of a down-hole oil water separation system. Despite performance and functionality of cyclones not being fully understood, they have created new possibilities for separating fluid down-hole for the producing formation and injecting separated water far away from the production interval. Before placing cyclones into practice, a study of fluid properties, well geometry, and characteristics of the formation can yield valuable information about the applicability and efficiency of DOWS.

In this study, Computational Fluid Dynamic (CFD) was used to determine the effect of changes in API oil gravity, flow rates and cyclone geometry in order to understand the behaviour of LLHC in down-hole conditions. CFD is a tool that can predict the quantity of oil flow into surface, the quality of injected water into formation, split ratio, separation efficiency, mass transfer and related phenomena by solving numerically set of governing equations defining the fluid behavior in a DOWS. 


\section{ACKNOWLEDGEMENT}

This project was initiated by Dr. H. Ilkin Bilgesu, to investigate the possibility of using Down-hole Oil-Water Separation in mature oil fields. To fully understand this project, some technical knowledge of Computational Fluid Dynamics (CFD) is helpful.

During the project, I have been very fortunate to have Dr. Bilgesu as my adviser and committee chair. I appreciate his guidance, where the entire aspect of Petroleum Engineering is included.

I am very grateful to Prof. Samuel Ameri for his help and encouragement during my study at WVU. I would like to thank Dr. Daniel E. Della-Giustina for serving as a committee member.

I would also like to mention Beverly Matheny, our Administrative Assistant, and Nancy Ireland for their help and support during this research. 


\section{TABLE OF CONTENT}

Page

ABSTRACT ................................................................................................. ii

ACKNOWLEDGEMENT .......................................................................iii

LIST OF FIGURES............................................................................. vi

LIST OF TABLES..................................................................................vii

NOMENCLATURES .................................................................................viii

CHAPTER I: INTRODUCTION .................................................... 1

1.1 PRODUCED WATER PROBLEMS.................................................1

1.2 CFD APPLICATION IN PETROLEUM ENGINEERING .................2

1.3 HYDRO-CYCLONE OPERATION IN DOWN-HOLE ........................3

1.4 THE PERFORMANCE FACTORS OF THE CYCLONES ................6

CHAPTER II: LITERATURE REVIEW ....................................9

2.1 DOWN-HOLE OIL-WATER SEPARATION ..................................9

2.2 DOWN-HOLE SEPARATION SYSTEM ...........................................9

2.3 BACKGROUND OF DOWS TECHNOLOGY ...................................10

2.4 WELL CANDIDATE SELECTION .................................................. 13

2.5 LIMITATION OF DOWS................................................................14

2.6 FIELD TESTING ..........................................................................15

2.7 OBJECTIVE OF THE STUDY ......................................................... 17

CHAPTER III: LIQUID- LIQUID SEPARATION ....................... 18

3.1 GRAVITY SEPARATION .................................................................. 18

3.1.1 Newton's Law ........................................................................18

3.1.2 Stoke's Law............................................................................19

3.2 FACTORS INFLUENCING THE SEPARATION OF LIQUIDS .....21

3.2.1 Density ....................................................................................................22

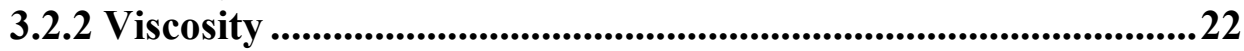

3.2.3 Demulsifiers .........................................................................23

3.2.4 Enforced Separation of Water from Oil ...................................23

3.2.5 Settling Velocity .............................................................................24

3.2.6 Droplet Diameter ..........................................................................24

3.2.7 Over flow Rate..................................................................................25

3.2.8 Dispersion Disengagement in a Gravity Settler ..........................26

3.2.9 Coalescence.....................................................................................28

3.2.10 Turbulence.........................................................................29 
CHAPTER IV: HYDRO-CYCLONE PROCESS MODELING........30

4.1 HYDRO-CYCLONE GEOMETRY ...................................................31

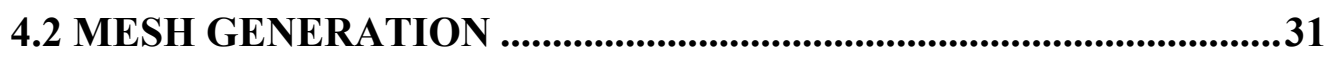

4.3 FLUENT MODELING OVERVIEW ...............................................34

4.4 SOLVER SELECTION ..............................................................................35

4.4.1 Segregated Solution Method ...............................................................35

4.4.2 Modeling multiphase flow ....................................................................37

4.4.3 Material Types and Properties ..........................................................39

4.4.4 Operating Pressure ......................................................................................40

4.4.5 Boundary Condition .................................................................................4 41

4.5 SOLUTION ALGORITHM ........................................................................43

4.5.1 Continuity Equation for Mixture Model ........................................43

4.5.2 Momentum Equation..............................................................................43

4.5.3 Volume Fraction of Secondary Phase ..............................................44

4.5.4 Slip Velocity and Drift Velocity ........................................................44

4.6 SOLUTION PROCEDURE OVERVIEW ................................................46

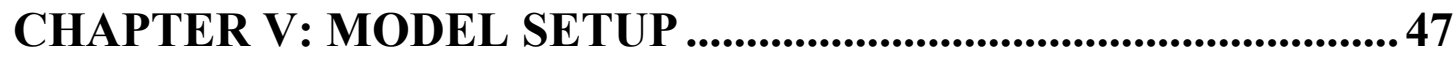

5.1 PHYSICAL MODEL .................................................................................47

5.3 DEFINING MATERIALS..........................................................................49

CHAPTERVI: DISCUSSION OF RESULTS ...............................50

6.1 MODEL VERIFICATION................................................................50

6.2 PARAMETRIC STUDY ..........................................................................53

6.3 EFFECT OF OIL PROPERTIES AND FLOW RATE..........................53

6.4 THE EFFECT OF INLET CONFIGURATION..................................59

CHAPTER VII: CONCLUSIONS AND RECOMMENDATIONS.. 62

7.1 CONCLUSIONS .............................................................................................62

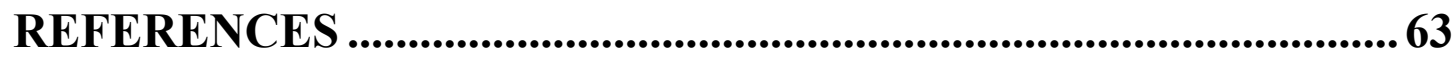




\section{LIST OF FIGURES}

Page

Figure 1. 1: Features of Hydro-cyclone 4

Figure 2.1: DOWS Scheme 11

Figure 2.2: Well VM-097 DOWS Equipment 16

Figure 3.1: Drag Coefficient of Rigid Spheres 19

Figure 3.2: The influence of density, viscosity, and water droplets in separation efficiency 22

Figure 3.3: Disengagement of continuous settler 27

Figure 3.4: Chimneying of feed dispersion in a deep settler 28

Figure 4.1: CFD Modeling Structure $\quad 30$

Figure 4.2: Hydro-cyclone Dimensions

Figure 4.3: CFD Modeling Overview

Figure 4.4: Procedure for Segregated Solution Method 36

Figure 4.5: Solution Procedure 46

Figure 5.1: Created Grid $\quad 48$

Figure 6.1: Static Pressure Profile $\quad 51$

Figure 6.2: Velocity profile in cyclone (iso-surface)

Figure 6.3: Profile of oil volume fraction $\quad 52$

Figure 6.4: Turbulence profile (Iso surface)

Figure 6.5: Profile of oil volume fraction $\left(15^{0} \mathrm{API}\right)$

Figure 6. 6: Variation of cyclone efficiency with well flow rate for four different oil densities $\quad 56$

$\begin{array}{ll}\text { Figure 6. 7: Velocity profile } & 57\end{array}$

Figure 6.8: Profile of oil volume fraction $\left(35^{\circ} \mathrm{API}\right)$

Figure 6.9: Variation of cyclone efficiency with oil density for four different well flow rates

Figure 6.10: Variation of cyclone efficiency with oil density for two different flow rates with $\begin{array}{lr}\text { smaller inlet size } & 60\end{array}$

Figure 6.11 Variation of cyclone efficiency with well flow rates for two different inlet design 


\section{LIST OF TABLES}

Page

Table 1: Well VM-097 production history before and after DOWS installation. 15

Table 2: Dispersion discriminant [10] 26

Table 3: Factors affecting coalescence time 29

Table 4: Guide lines for successful separators 29

Table 5: Applicability of DSP Model 38

Table 6: Applicability of Mixture Model 38

Table 7: Applicability of VOF Model 39

Table 8: Recommended procedure for selecting operating pressure 40

Table 9: Dimensions of Physical Model 47

Table 10: Material Properties used for this study 49

Table 11: Well VM: production without and, with DOWS and CFD simulation result 50

Table 12: Effect of oil density in oil-water separation with DOWS at WOR value of 97.754

Table 13: Effect of oil density with DOWS at WOR of 98\% 56

Table 14: Effect of oil density in oil-water separation with DOWS in WOR of $97 \% \quad 58$

Table 15: Effect of oil density in oil-water separation with DOWS in WOR of $96 \%$

Table 16: Effect of reduced inlet in oil-water separation with WOR of $98 \%$

Table 17: Effect of reduced inlet in oil-water separation with WOR of $97 \%$ 


\title{
NOMENCLATURES
}

\author{
${ }^{0} \mathrm{API}$ \\ American Petroleum Institute API $=(141,5 /$ liquid specific gravity \\ $\left.\left(60^{\circ} / 60^{\circ} \mathrm{F}\right)\right)-131.5$ \\ $\mathrm{C}_{\mathrm{D}} \quad$ Drag coefficient \\ CFD Computational Fluid Dynamics \\ $\mathrm{d}_{\mathrm{pC}} \quad$ Droplet of continue phase \\ D Internal Diameter, $\mathrm{m}$ \\ DOWS Down-hole oil/water separation \\ $\mathrm{D}_{\mathrm{p}} \quad$ Droplet diameter, $\mu \mathrm{m}$ \\ F Split ratio \\ F Turbulence factor \\ $\mathrm{F}_{\mathrm{D}} \quad$ Drag force, $\mathrm{kgm} / \mathrm{s}^{2}$ \\ g Gravity of acceleration, $\mathrm{m} / \mathrm{s}^{2}$ \\ $\mathrm{K}_{\mathrm{CR}} \quad$ Critical particle diameter \\ $\mathrm{p} \quad$ Operating Pressure, bar \\ ppm Part per million \\ Q Continuous phase volumetric flow rate, $\mathrm{m}^{3} / \mathrm{s}$ \\ $\mathrm{Q}_{\mathrm{h}} \quad$ Heavy liquid volumetric flow, $\mathrm{m}^{3} / \mathrm{s}$ \\ $\mathrm{Q}_{1} \quad$ Light liquid volumetric flow, $\mathrm{m}^{3} / \mathrm{s}$ \\ $\mathrm{R} \quad$ Radius of cylinder, $\mathrm{m}$ (radius of separation equipment) \\ $\mathrm{T} \quad$ Operating temperature, ${ }^{\circ} \mathrm{C}$ \\ $u_{d} \quad$ Settling velocity of the dispersed phase, $\mathrm{m} / \mathrm{s}$ \\ $\mathrm{u}_{\mathrm{t}} \quad$ Terminal velocity, $\mathrm{m} / \mathrm{s}$ \\ V Particle fluid relative velocity, $\mathrm{m} / \mathrm{s}$
}




\begin{tabular}{|c|c|}
\hline $\mathrm{v}_{\mathrm{c}}$ & Velocity of continuous phase, $\mathrm{m} / \mathrm{s}$ \\
\hline $\mathrm{v}_{\mathrm{c}}$ & Centrifugal settling velocity, $\mathrm{m} / \mathrm{s}$ \\
\hline $\mathrm{v}_{\mathrm{g}}$ & Gravitational settling velocity, $\mathrm{m} / \mathrm{s}$ \\
\hline $\bar{v}_{m}$ & Mass average velocity, $\mathrm{m} / \mathrm{s}$ \\
\hline $\mathrm{v}_{\mathrm{s}}$ & Liquid settling velocity, $\mathrm{m} / \mathrm{s}$ \\
\hline $\mathrm{V}$ & Volume, $\mathrm{m}^{3}$ \\
\hline$\omega$ & Centrifugal velocity, $\left(\mathrm{m} / \mathrm{s}^{2}\right)$ \\
\hline$\rho$ & Density, $\mathrm{kg} / \mathrm{m}^{3}$ \\
\hline$\rho_{\mathrm{o}}$ & Oil phase density, $\mathrm{kg} / \mathrm{m}^{3}$ \\
\hline$\rho_{\mathrm{w}}$ & Water phase density, $\mathrm{kg} / \mathrm{m}^{3}$ \\
\hline$\rho_{\mathrm{h}}$ & Heavy phase density, $\mathrm{kg} / \mathrm{m}^{3}$ \\
\hline$\rho_{1}$ & Light phase density, $\mathrm{kg} / \mathrm{m}^{3}$ \\
\hline$\rho_{\mathrm{m}}$ & Mixture density of water/oil, $\mathrm{kg} / \mathrm{m}^{3}$ \\
\hline$\theta$ & Dimensionless factor to determine continuous phase \\
\hline$\mu_{\mathrm{c}}$ & Viscosity of continuous phase, $\mathrm{kg} / \mathrm{ms}$ \\
\hline$\mu_{\mathrm{h}}$ & Viscosity of heavy phase, $\mathrm{kg} / \mathrm{ms}$ \\
\hline$\mu_{1}$ & Viscosity of light phase, $\mathrm{kg} / \mathrm{ms}$ \\
\hline$\mu_{m}$ & Viscosity of mixture, $\mathrm{kg} / \mathrm{ms}$ \\
\hline$\alpha_{k}$ & Volume metric fraction of the heavy phase \\
\hline$v_{d r, k}^{-}$ & Draft velocity of secondary phase \\
\hline$\tau_{p}$ & Particle relaxation time \\
\hline
\end{tabular}




\section{CHAPTER I: INTRODUCTION}

\subsection{PRODUCED WATER PROBLEMS}

Water is by far the largest waste stream associated with oil and gas production and it is unimaginable to find an oil reservoir absolutely free from connate water. Separation of water from oil and gas is the oldest practice in the petroleum industry.

When oil is retrieved from underground wells, it is often accompanied by significant amounts of water, called produced water. Produced water refers to the water brought up from the hydrocarbon bearing strata during the extraction of oil and gas. This water can include formation water, injection water, and any (waste) surfactants added down-hole or during the oil/water separation process. Produced water always contains dispersed and dissolved oil and other varieties of dissolved inorganic and organic compounds, suspended solids such as formation fines, sand, scales and corrosion products. This mixture of oil and water needs to be separated and the water disposed of or re-injected into the reservoir before the oil can be exported to refineries

Water management has become an important issue of hydrocarbon production, since the produced water increases as a field gets older and because of the dramatically increasing cost of water handling, such as separation and treatment. In addition, the withdrawal of water contributes to the reduction of pressure and water re-injection is required to maintain reservoir pressure in order to enhance oil recovery.

Traditionally, large, heavy gravity separators have been used to separate oil and water. Due to the slug flow of the oil/water interface these separators are not stable and separation efficiency is reduced, making it harder to produce only oil at the surface, thus creating economic and environmental challenges.

As the oil concentration changes, such as in oily wastewater containing more than $90 \%$ of water, oil content can be as low as 50 ppm or as high as 500 ppm. In a mature oilfield oil 
content can vary between $2 \%$ and $10 \%$, depending on the oilfield's characteristics. The separation process varies based on the oil-water mixture. Most commercially available oil-water separators rely on the gravity movement but this separation method is not effective in less-dense oil in down-hole oil-water separation.

With their compact size, hydro-cyclones can be used to replace large surface separators, both on newly built platforms and existing ones with water- handling constraints that usually occur in mature fields. Liquid-liquid hydro-cyclones can also be used as an integral part of a down-hole oil-water separation system. They created new possibilities for separating fluid down-hole in the producing formation and injecting separated water far away from the production interval. The cyclone divides the liquid mixture into two streams as oil stream to be lifted to the surface and an oil-depleted water stream to be injected into a disposal zone. Before putting cyclones into operation, one has to investigate fluid properties, well geometry, well completion and characteristics of the formation.

Computational fluid dynamic (CFD) simulations and modelling were conducted to understand the behaviour of the liquid-liquid hydro-cyclone (LLHC) in down-hole conditions. CFD is a tool that can predict fluid flow, split ratio, total separation efficiency, pressure drop, heat and mass transfer, chemical reactions and related phenomena by solving sets of governing equations.

\subsection{CFD APPLICATION IN PETROLEUM ENGINEERING}

Computational Fluid Dynamics (CFD) is a part of fluid mechanics that brings to perfection for experimental and analytical fluid engineering. CFD is the science of

predicting fluid flow, heat and mass transfer, chemical reactions and related phenomena by solving numerically sets of governing equations. Its capabilities and application have been widely expanded, giving, experts in the petroleum industry confidence to use this predictive tool in many applications ranging from drilling to production and processing. 
CFD models were applied to simulate the hydrodynamics of complex machinery and equipment involving moving parts, erosion, heat transfer, chemical reactions and multiphase flow. Fluent models have been developed and tested with applications such as; drill bits, pumps, static mixers, distillation trays, separators, packed beds, fluidized beds, reactors and multistage compressors. Fluent solves transport equations needed for each application. It is capable of solving a fast array of a complex phenomenon using a storehouse of physical models. We can apply CFD to many problems in petroleum engineering, such as: [1]

- Drilling fluids, such as mud (non-Newtonian viscosity laws)

- Production in oil fields, including flow around down-hole injectors

- Flow involving two-phase and three-phase (gas-solids, liquid-solids or liquidliquid mixtures).

- Compressors, pumps, propellers and impellers.

- Flow in refinery equipment such as crude oil desalters and reactors.

- Erosion and other effects of particle-laden flows (comprehensive particle-tracking algorithm)

\subsection{HYDRO-CYCLONE OPERATION IN DOWN-HOLE}

The hydro-cyclone is a static separator which utilizes fluid pressure energy to create rotational fluid motion. The hydro-cyclone separates lighter components from a liquid medium which is usually water. It was due to this water medium prevalence that the name "hydro-cyclone" was coined. In contrast to sedimenting centrifuges, hydrocyclones have no rotating parts and necessary vortex is produced by pumping the fluid tangentially into a stationary cone-cylindrical body. The vessel at the point of entry is usually cylindrical. It can remain cylindrical over its entire length, thought it is usually tapered. [2] Figure 1 shows what is generally accepted as the normal design of the hydrocyclone. The cylindrical part is closed at the top by a cover, through which the liquid overflow pipe, or vortex finder, provides outlet for lighter components. Classification of the hydro-cyclone is often in terms of the cylindrical section diameter. Individual hydrocyclone diameters range from $10 \mathrm{~mm}$ to $2.5 \mathrm{~m}$. 

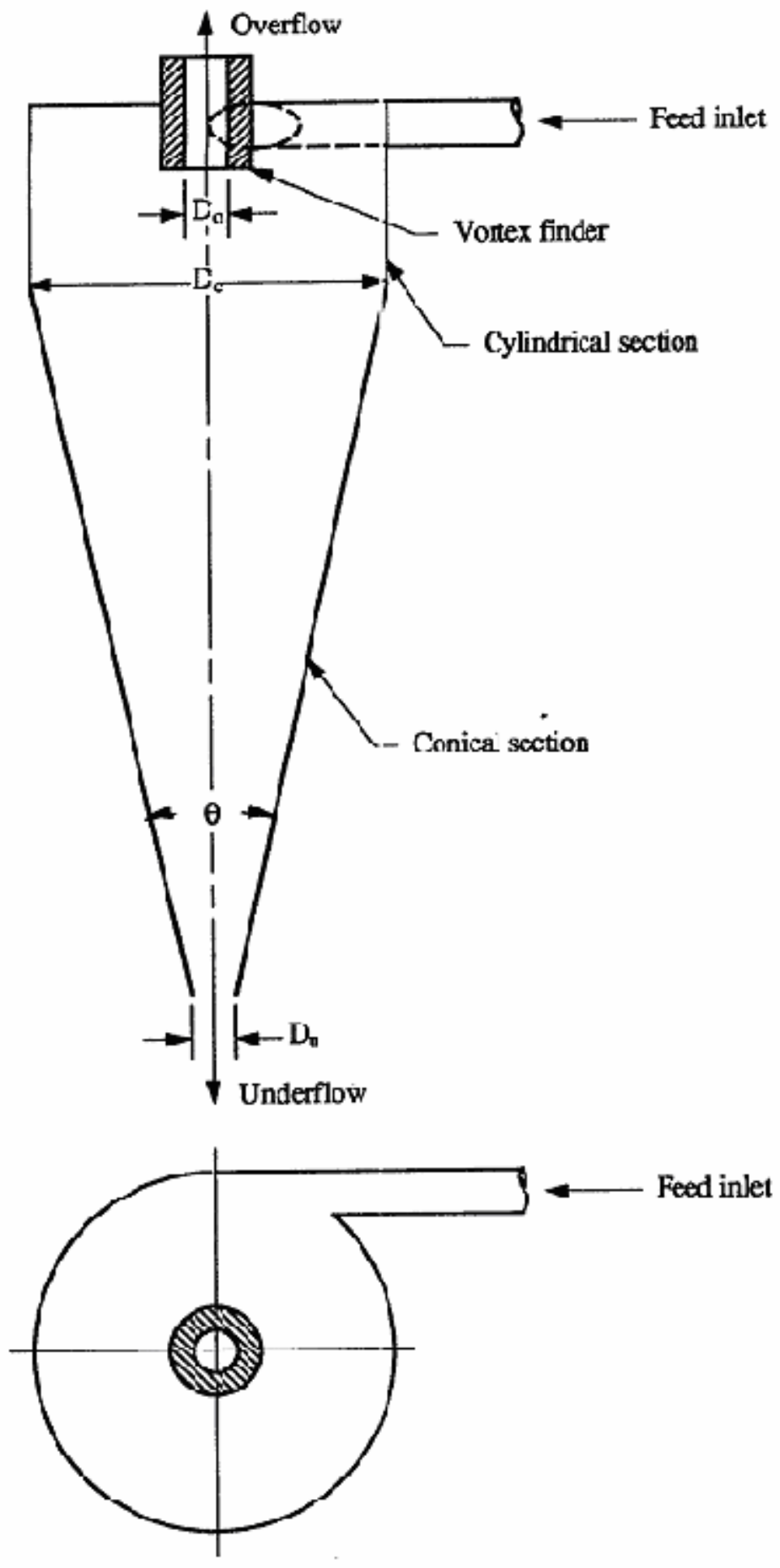

Figure 1. 1: Features of Hydro-cyclone [2] 
Hydro-cyclone separates substances of different densities by centrifugal force and then the lighter phase (oil) flows to the overflow outlet and the heavier one (water) to the underflow outlet. Perfect separation of oil and water mixture is not possible.

Since the early 1980s, the oil industry has employed hydro-cyclone to separate oil and water because of its compactness, low resistance time, lack of moving parts and absence of fine clearance elements that could be blocked or need replacement.

Early studies by Colman and Thew [3] were used to design hydro-cyclones to de-oil produced water to discharge to the sea, de-water oil to sales specifications, treat oil spills at the sea, and, more recently, in down-hole oil-water separation.

Hydro-cyclone performance is measured in terms of separation efficiency, controlled by inlet fluid properties (differential fluid density, free gas and oil concentrations) and operational conditions (split ratio, flow rate and pressures). Flow capacity of one hydrocyclone is low compared with the total flow of a well. Therefore, hydro-cyclones are arranged vertically in series. The number of hydro-cyclones needed depends on the total flow rate from the reservoir. [4]

There are three types of hydro-cyclones used in down-hole separation.

1. Bulk hydro-cyclones,

2. De-watering hydro-cyclones

3. De-oiling hydro-cyclones.

These hydro-cyclones are more or less the same design but operate differently. The bulk hydro-cyclone splits the mixture of oil and water produced from the reservoir into one oil-rich flow and one water-rich flow. The oil-rich flow goes to the de-watering hydro-cyclones where most of the water is removed resulting in clean oil phase.

The water flow from the bulk hydro-cyclone goes to de-oiling hydro-cyclones where oil is removed. De-oiling and de-watering hydro-cyclones prioritize one phase, water or oil respectively. Thus one clean phase and one polluted phase exit the de-oiling hydrocyclone and de-watering hydro-cyclone, respectively. [5] 
The physical separation conditions down-hole are quite different from the surface conditions. Temperature and pressure drop as the fluid flows to the surface. Due to high temperature and pressure, fluid viscosity is at the minimum at the bottom of a well. Low viscosity improves separation and reduces pressure loss in the hydro-cyclone. High pressure and temperature also reduce shear forces. A droplet collapses easier if shear forces are small, resulting in improved hydro-cyclone efficiency.

Hydro-cyclones are widely used in produced water treatment. An analysis of physical separation conditions both surface and down-hole suggest that hydro-cyclones can be used successfully for down-hole separation.

Down-hole oil-water separation may offer several reservoir benefits. This technology may reduce the hydrostatic column, which is significant for low-pressure reservoirs, the life of the reservoir may be extended, and production will be increased. Gas lifting will be postponed by applying this system. [5]

\subsection{THE PERFORMANCE FACTORS OF THE CYCLONES}

Hydro-cyclone operation is influenced by a number of parameters, some of which are not fully understood at this moment. The parameters that are affecting efficiency of separation are as follows:

- The split ratio (F). Defined as the ratio of the overflow rate (oil) to the total inlet flow rate (liquid). Previously researchers thought $\mathrm{F}>5 \%$ was average, but now using small upstream outlet diameter, F can be reduced to about 1\% [3]. The split ratio is expressed as:

$$
\mathbf{F}=\frac{q_{\text {over }- \text { flow }}}{q_{\text {inlet }}} * 100
$$

Where:

$\mathrm{q}_{\text {over-flow }}=$ the total oil flow rate at the upper outlet of the hydro-cyclone, $\mathrm{m}^{3} / \mathrm{s}$ 


$$
\left.\mathrm{q}_{\text {inlet }}=\text { the total inlet flow rate (oil }+ \text { water }\right), \mathrm{m}^{3} / \mathrm{s}
$$

(b) Oil Separation Efficiency (cff): It is the practical interpretation of separation of the purity of individual discharge streams. Many references quantify the relative phase composition of the separated streams in the form of a percentage by volume measurement. [6]

$$
\varepsilon f f=\frac{q_{\text {oil-overflow }}}{q_{0 \text { il-inlet }}} * 100 \%
$$

Where:

$\mathrm{q}_{\text {oil-overflow }}=$ the flow rate of oil at the overflow

$\mathrm{q}_{\text {oil-inlet }}=$ the flow rate of the oil at inlet.

(c) The pressure drop. It affects pumping requirements, and represents energy required to spin the incoming fluid. The pressure drop of individual cyclones ranges from 5 to $90 \mathrm{psi}$, with smaller units usually operated at a higher pressure drop than the large ones. Under normal operation there are two measured pressure drops across a hydro-cyclone. One is the difference between inlet and rejected pressure, and the other is the difference between inlet and outlet pressure. The first one is always greater than the second. The relationship between two different pressure drops is called pressure difference ratio (PDR) and is defined as [6]:

$$
P D R=\frac{P_{\text {in }}-P_{r e j}}{P_{\text {in }}-P_{\text {out }}}
$$

Where:

$\mathrm{P}_{\text {in }}=$ inlet pressure,

$\mathrm{P}_{\text {rej }}=$ the rejected pressure or overflow outlet (oil)

$\mathrm{P}_{\text {out }}=$ the pressure of underflow outlet (water) 
(d) Flow rate. Minimum flow rate is necessary in order to establish the vortex motion and create the central core. Generally, as flow rate increases, the efficiency of separation increases. Lower flow rates create longer residence times but lower acceleration forces. Conversely, higher flow rates result in higher acceleration forces and smaller residence times. Hydro-swirl performance is independent of flow rate. [7]

(e) The density difference. This is the biggest driving force for the separation. The bigger the difference, the more rapid is the separation.

(f) The temperature. A temperature increase will affect density and also lower viscosity, resulting in better separation.

(g) The particle cut size: This is the size of a particle that would have a $50 \%$ chance of exiting at either the underflow or overflow. In a liquid-liquid separation, the mean droplet size is very important since large droplets will move more rapidly to the central flow or outflow, depending on their density [8]. 


\section{CHAPTER II: LITERATURE REVIEW}

\subsection{DOWN-HOLE OIL-WATER SEPARATION}

The conventional production process involves producing both oil and gas to the surface and separating them at the surface. This separation occurs through the use of gravity settlers such as vessel, plate coalescence and hydro-cyclone.

However, as a field matures and oil and gas production peaks, there is often an associated increase of produced water and a corresponding increase in both lifting and water disposal costs, that leads to an additional increase in maintenance of equipment and down-hole treatment for corrosion, bacteria, scale and naturally occurring radioactive material (NORM). Operators have different options in either disposing of water or injecting it into the reservoir. There is also growing concern related to handling of produced water and the environmental impact of water dumping. It became a major issue, in industry especially, to relate surface damage to spillage, or subsurface contamination of drinking water being due to poor injection activity. The Down-hole oil-water separation (DOWS) technique separates oil and water down-hole, lifts oil to the surface, and injects water back in the formation. DOWS can increase oil production and reduce water handling cost by reducing the volume of water produced to the surface. [9]

\subsection{DOWN-HOLE SEPARATION SYSTEM}

Down-hole separation principles are similar to traditional surface separation governed by Stoke's Law of droplet settlement. The two primary components are an oil /water separator and at least one pump to lift oil to the surface and to inject water into underground formations. The system was designed to incorporate all components as one unit with simple interface between them. There are two basic DOWS systems so far developed; one type of separator is using hydro-cyclone to separate mechanically oil and water. The other is gravity separation that takes place in the wellbore. 
In down-hole separation, it is possible to arrange the separators in different ways, among which the two basic ones are the following:

- Pull through: The separator is placed upstream of the pump.

- Push-through: The separator is installed downstream of the pump.

If the separator is considered independently from the other equipment, it may be installed at the same location as a set of static cyclones, either pull through or push through [10] Hydro-cyclones based in DOWS have shown greater acceptance all over the world within their limitations. The separation mechanism is the same as a cyclone separator but the down-hole high pressure is the driving force for the separation, as cyclones do not have moving parts. Failures commonly occur in a cyclone separator. They can be classified as, mechanical failures and process failures.

Mechanical failure includes pump/motor failure, seal failure and solid production failure. Process failure includes unexpected fluid shear, heavy crude, and solid presence in the fluid. Experience of DOWS all over the world shows different failures in different applications. A typical DOWS system is shown in Figure 2.1.

\subsection{BACKGROUND OF DOWS TECHNOLOGY}

Down-hole oil /water separation technology has been in the oil and gas industry since the 1990s. Despite offering an economic and environmental advantage, only a limited number of this system has been installed in oil and gas wells. Most of DOWS technology system installed in oil wells has been deployed with 7 inch or 5.5 inch or even smaller casing size. This system was designed for wells producing less than 5000 BPD and has electrical submersible pumps generating less than $300 \mathrm{HP}$. 


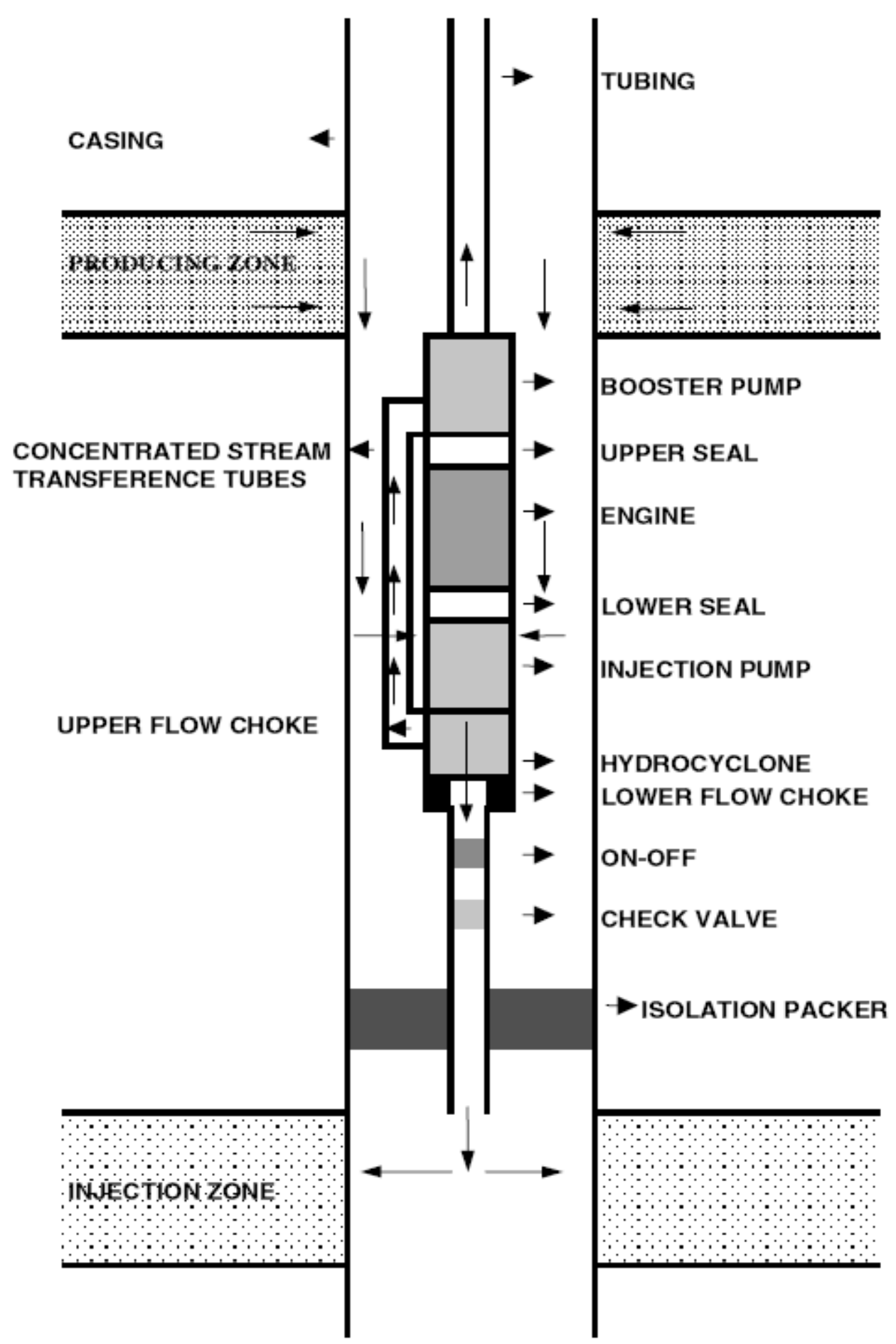

Figure 2.1: DOWS Scheme [3] 
However, more than 100 DOWS have been installed worldwide. Geology and performance of 37 of these installations are summarized. Twenty of the DOWS installations were in wells located in carbonate formations and 16 were in wells located in sandstone formations. The DOWS appeared to work better in carbonate formations, showing an average increase in oil production of $47 \%$ (compared to an average of $17 \%$ for sandstone formations) and an average decrease in water brought to the surface of $88 \%$ (compared to $78 \%$ for sandstone formations). Oil production increased in 19; decreased in 12, remains the same in 2 installations and an unspecified 4 installations did not report oil production increase. [11]

The top three performing wells with hydro-cyclone DOWS had oil production increases of $457 \%$ to $1162 \%$, while one well's production decreased. In the top performing well, oil production increased to $164 \mathrm{bbl} / \mathrm{d}$ from $13 \mathrm{bbl} / \mathrm{d}$. On the other hand, in top three gravity separator DOWS installations oil increases of $106-233 \%$ were observed while in one well production decreased. In the top performing well, oil production increased to 10 $\mathrm{bbl} / \mathrm{d}$ from $3 \mathrm{bbl} / \mathrm{d}$.

In the 29 trials for which both pre-installation and post-installation water production data were available, water volume brought to the surface decreased from $97 \%$ to $14 \%$ with 22 of 29 trials exceeding a $75 \%$ reduction. Despite with early success, numerous other installations either did not work well from the beginning or declined in performance within a few weeks or months. Some failure resulted from improper selection and design of the installations because the operators were not willing to take a risk to damage good performing wells with a new device, and therefore they selected less than optimal candidate wells. Other failures resulted from insufficient distance between producing and injection intervals, which allows injected fluid to migrate to producing zones. Two installations suffered from low injectivity of the receiving zone; in both cases, incompatibility fluids contacted sensitive reservoir sands, decreasing their permeability. Other installations suffered corrosion or scaling because of incompatible chemistry between produced and injected fluids. Several installations experienced problems with 
excessive sand production that either clogged the formation or eroded the DOWS component [11].

Other factors that have limited the use of this technology include well completion cost, candidate wells, equipment design and reservoir-related parameters such as productivity, injectivity, solids, relative zone location and zone characteristics.

\subsection{WELL CANDIDATE SELECTION}

This technology cannot be applied in all wells because formations in some reservoirs are not conducive to down-hole separation and injection. An accurate selection of the wells has a direct effect on the success of the system. The following features are required for the system to be used. [12]

1. Wells which have a depleted horizon, with low static pressure or most likely to receive water injection, will turn into potential candidates for the DOWS technology.

2. From production perspective, only wells which are having a water cut of $94 \%$ or more will be considered for this technology.

3. The reservoir has to contain sufficient incremental reserves and provide a suitable disposal zone.

4. Injection zone must have sufficient permeability and porosity to accept segregated produced water.

5. The casing has to be at least 5.5 inches in diameter.

6. Well bore has to have a good mechanical integrity.

7. Minimum distance of about 80 feet must exist between the production zone and disposal zone.

8. The well bore had to be already open below the production zone so that additional drilling would not be needed.

9. Characteristics of produced water must be compatible with the injection zone. It is usually inadvisable to mix water from carbonate and sandstone formations. 
10. Wells producing cold, heavy crude oil with API gravity of $10^{\circ}$ or less may not be good candidates for this technology due to poor separation.

11. Deviated wells will be difficult for applying this technology.

\subsection{LIMITATION OF DOWS}

DOWS technology is very complex and premature. All field tests show that few existing installations are successful. The technology cannot be used in just any field as there are some restrictions for its use. Down-hole hydro-cyclone separators cannot produce both clean water and dehydrated oil streams at the same time. Hydro-cyclones require some fluid properties for an effective separation and not all oil fields meet the requirements. Some of the limitations are related to the system itself while others are inherent to the usage of the system. Technological progress may reduce limitations. The following are some of the limitations of the system. [12]

1. Well-bore space is very limited; Hydro-cyclone designed in this particular operation or in down-hole must be narrow and tall; therefore, minimum casing size requirement must be 5-1/2 inch.

2. ESP-DOWS-the engine must be installed below the productive area to allow its refrigeration; otherwise, an engine sleeve must be used when the casing size allows it.

3. Based on previous experience, the system worked better in carbonates compared to sandstone formations so it is advisable to avoid sandstone formations.

4. Reservoirs that have a history of sand producing may not be suitable for this system due to plugging within the system.

5. This system can be applied to wells producing high volume of water-oil ratio (WOR).

6. Oil density must be higher than $985.052 \mathrm{~kg} / \mathrm{m}^{3}\left(12^{\circ} \mathrm{API}\right)$.

7. Minimum difference of specific gravity between oil and water should be 0.05 .

8. Oil content (typically between 10 and $200 \mathrm{ppm}$ of oil) in the injecting water can damage the formation, especially those that do not have oil residual saturation. 
9. Impossible to effectively stimulate the areas below the pump without of pulling.

10. It is preferable not to apply this technology to deviated wells.

\subsection{FIELD TESTING}

An early application of DOWS was in the LaVentana fields in the Cuyo basin, Mendoza province, Argentina, discovered in 1957. LaVentana produces from the Barrancas formation, TRC (Top Red Conglomerate) and BRC (Base Red Conglomerate) reservoirs with $30^{\circ} \mathrm{API}$ oil gravity coupled with a high percentage of water. A pilot field trial was carried out in well VM-097 using DOWS technology. The well was worked over and DOWS equipment was installed prior to the settlement of a ' $D$ ' packer to separate the injection sands from the productive TRC and BRC reservoirs. As shown in Figure 2.2, the equipment had submersible pumps and two parallel hydro-cyclone tubes with a calibrated choke for the superior flow of $9.95 \mathrm{~mm}$ with an injection pump. This well was producing a total fluid of $385 \mathrm{~m}^{3} /$ day with $97.7 \%$ of water cut through an electricalsubmersible pump that allows the high-pressure fluid discarded by the pump to enter tangentially to the hydro-cyclone tube, generating centrifugal forces which divide the flow into two different streams. The result was significant reduction of water to the surface and increased oil rate. Table No 1 is a summarized production history of well VM-097 before and after DOWS installation.

Table 1: Well VM-097 production history before and after DOWS installation.

\begin{tabular}{|l|c|c|}
\hline & $\begin{array}{l}\text { Before DOWS } \\
\text { installation }\end{array}$ & $\begin{array}{l}\text { After DOWS } \\
\text { installation }\end{array}$ \\
\hline Gross rate, $\mathrm{m}^{3} /$ day (STB/D) & $385(2420)$ & $385(2420)$ \\
\hline Oil to surface, $\mathrm{m}^{3}$ / day (STB/D) & $8.855(55.7)$ & $8.1(50.9)$ \\
\hline Water to surface $\mathrm{m}^{3} /$ day (STB/D) & $376.145(2370)$ & $72.9(459)$ \\
\hline Water injected, $\mathrm{m}^{3}$ / day (STB/D) & $0(0)$ & $304(1910)$ \\
\hline Surface water cut, $\%$ & $\mathbf{9 7 . 7}$ & $\mathbf{9 0}$ \\
\hline
\end{tabular}




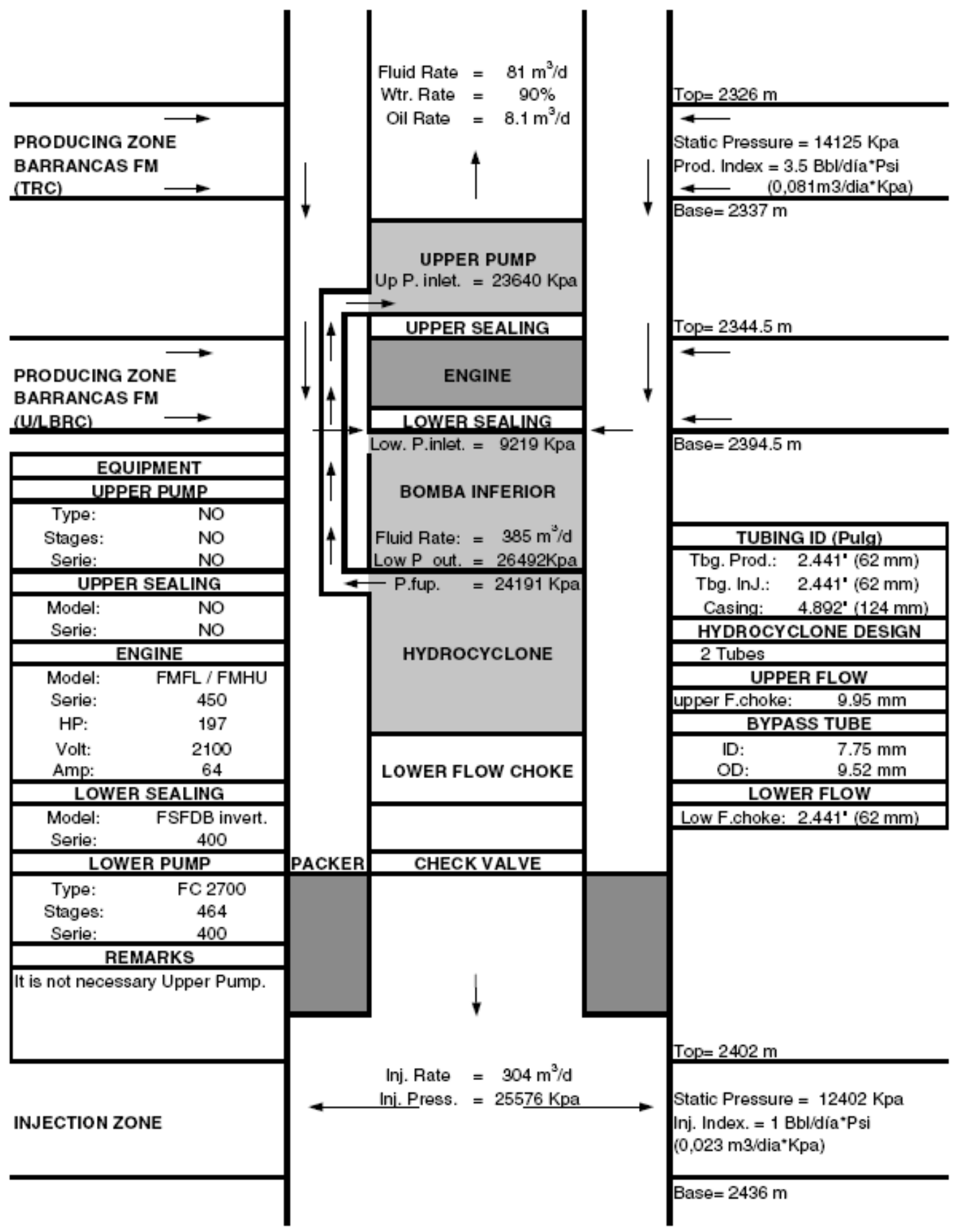

Figure 2.2: Well VM-097 DOWS Equipment [3] 


\subsection{OBJECTIVE OF THE STUDY}

The objective of this study is to investigate the performance and efficiency of a liquidliquid hydro-cyclone in down-hole conditions. The specific aim of this study is as follows:

- To develop a Hydro-cyclone performance model using CFD.

- To integrate the model into reservoir conditions.

- To test and verify this model against published field case.

- To develop relationship between reservoir, fluid properties and hydro-cyclone separation efficiency by applying computational fluid dynamics. 


\section{CHAPTER III: LIQUID- LIQUID SEPARATION}

\subsection{GRAVITY SEPARATION}

Gravity separation can happen when two immiscible liquid phases or liquid and gas phases are separated by the differences of their densities. Sufficient retention time must be provided in the gravity settler to allow the gravity separation to take place. In twophase liquid separation, heavy liquid droplets will settle out of the light liquid phase if the gravitational force acting on the heavy liquid droplets is greater than the drag force of the light phase flowing around the droplet.

The oil-water separation process is generally explained by particle dynamics. It is thought to be governed by Stokes Law for terminal velocity of spheres in a liquid medium using Newton's basic drag Equation [4].

Liquid droplets will either rise or settle in a separate immiscible liquid medium depending on the droplet density, droplet diameter, and drag coefficient. Reynolds number will determine the selection of appropriate gravity separation law.

\subsubsection{Newton's Law}

If a particle moves relative to the fluid in which it is suspended, the force opposing the motion is known as a drag force. Knowledge of the magnitude of this force is essential for the study of particle motion. Conventionally the drag force is expressed according to Newton's law:

$$
F_{D}=C_{D} * A * \frac{\rho v^{2}}{2}
$$

Where: $\quad \mathrm{F}_{\mathrm{D}}=$ Drag force, $\mathrm{kgm} / \mathrm{s}^{2}$

$\mathrm{v}=$ Particle fluid relative velocity, $\mathrm{m} / \mathrm{s}$

$\rho=$ Fluid density, $\mathrm{kg} / \mathrm{m}^{3}$

$\mathrm{A}=$ Area of particle projected in direction of motion, $\mathrm{m}^{2}$

$\mathrm{C}_{\mathrm{D}}=$ Drag coefficient, dimensionless. 
Newton's law is used for relatively large particles (approximately 1000 microns and larger) as seen in Figure 3.1 Newton's law for constant drag coefficient $\left(C_{D}=0.44\right)$ describes the gravity settling. The flow is fully turbulent when the Reynolds number is about 1000 to 200,000. On the other hand, Newton's principle indicates that settling velocity is strictly applicable only in the case of Newtonian fluids when the viscosity is independent of the shear rate and duration of shear.

The constant critical particle diameter $\left(\mathrm{K}_{\mathrm{CR}}\right)$ above which Newton's law will not apply is 18 , [13]. Newton's law is applicable when the droplet size is very large, and the required terminal velocity of such magnitude, that excessive turbulence is created. The upper limit of the Reynolds number is 200,000 . [14]

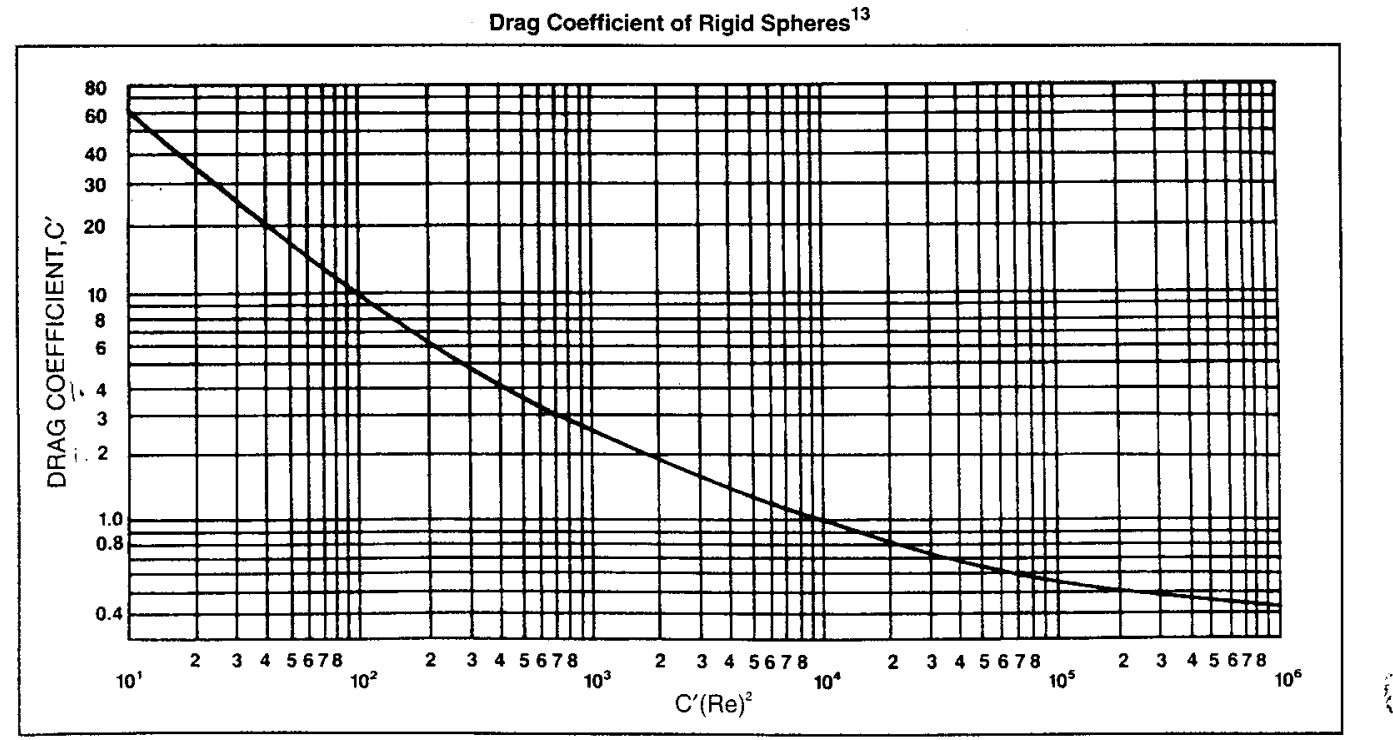

Figure 3.1: Drag Coefficient of Rigid Spheres [13]

\subsubsection{Stoke's Law}

Contrary to Newton's law, Stoke's law is used for smaller particles. Stoke's law is valid for the separation of liquids by utilizing the density differences between the liquids. Equation 5 shows that the factors that determine the settling velocity are the size of a droplet, the density difference between the separated liquids, viscosity of heavy phase and the gravitational force. Larger droplets, lower viscosity, and bigger density differences between the two liquids improve settling velocity. $[13,16]$ 
$v_{g}=\frac{\mathrm{d}_{\mathrm{p}}{ }^{2}\left(\rho_{w}-\rho_{\mathrm{o}}\right)}{18 \mu_{c}} \mathrm{~g}$

Where:

$v_{\mathrm{g}}=$ Gravitational settling velocity, $\mathrm{m} / \mathrm{s}$

$\mathrm{d}_{\mathrm{p}}=$ Droplet diameter, $\mathrm{m}$

$\rho_{\mathrm{w}}=$ Heavy phase- phase density, $\mathrm{kg} / \mathrm{m}^{3}$

$\rho_{\mathrm{o}}=$ Light-phase density, $\mathrm{kg} / \mathrm{m}^{3}$

$\mu_{\mathrm{c}}=$ Viscosity of continuous phase $\mathrm{kg} / \mathrm{ms}$

$\mathrm{g}=$ Gravitational acceleration, $9.81 \mathrm{~m} / \mathrm{s}^{2}$

According to Figure 3.1 a linear relationship exists between drag coefficient and the Reynolds number at Reynolds numbers (less than two). The droplet diameter corresponding to a Reynolds number 2 can be found using a value of 0.080 for $\mathrm{K}_{\mathrm{CR}}$. This is the lower limit of Stokes Law applicability having a droplet diameter of approximately three microns. The upper limit is about 100-150 microns. Therefore Stokes Law is applied as a basis for separation of liquids. Small droplets such as fog or mist cannot be separated practically by gravity. These droplets can be coalesced to form larger droplets that will settle by gravity.

Parameters in Equation 5 influence the separation process; efficiency of the system can be improved by modifying the parameters in the Stokes Law for the following characteristics:

\section{To increase in droplet diameter:}

- Add coalescing media

- Increase proportion of dispersed phase

- Add chemicals to promote coalescence

To increase gravitational force:

- Add cyclone inlet device

- Use centrifuges 


\section{To increase in density gradient:}

- Increase temperature

- Minor effect of heat, salinity, etc.

To decrease in viscosity of continuous phase:

- Add heat (increase temperature)

- Change oil phase to continuous phase

- Add chemicals. [17]

\subsection{FACTORS INFLUENCING THE SEPARATION OF LIQUIDS}

In theory, there are many factors that can enhance the quality of separation processes. It is desirable to consider those factors in order to understand cyclones or gravity settlers and other separation equipment. The different factors that need to be considered are:

- Density.

- Viscosity.

- Temperature.

- Flow rate.

- Settling velocity.

- Turbulence level.

- Coalescence.

- Dispersed phase and continuous phase.

Figure 3.2 shows the influence of density, viscosity, and water droplet size on separation efficiency. There are process constraints that cannot be controlled in separation process or can be controlled to a limited extent. These are:

- Process liquid and solute.

- Phase relationship of the dispersion.

- Flow rate, flow ratio and retention time of the dispersed phase and dispersion entering the separator.

- Temperature of operation dictates density, equivalent viscosity and interfacial tension. $[13,16]$ 

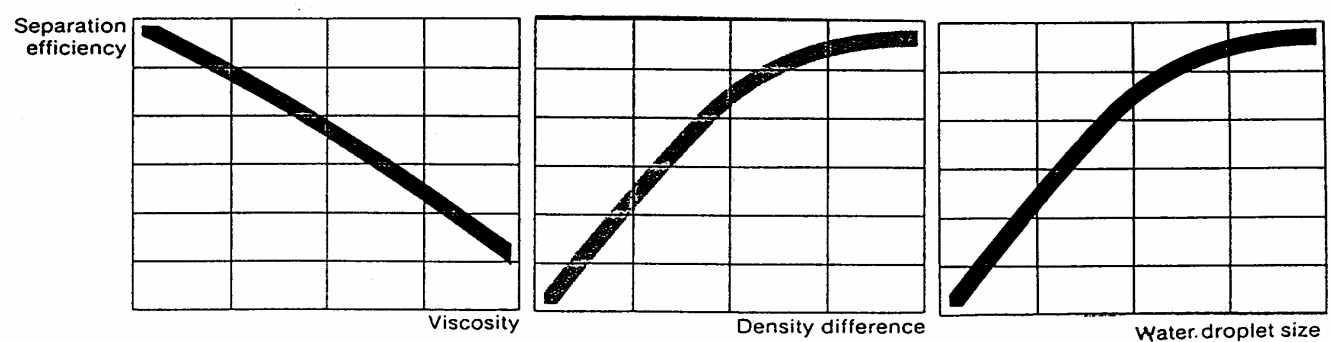

Figure 3.2: The influence of density, viscosity, and water droplets in separation efficiency [6]

\subsubsection{Density}

The nature and behavior of high-density crude oils include a number of undesirable characteristics such as their tendency to form emulsions due to the presence of waxes, asphaltenes and scale. This phenomenon of emulsion formation together with other properties such as high viscosity, typically low temperature, pressures and gas/oil ratio render these types of fluids extremely difficult to treat. The traditional way to approach these problems is to use a large amount of heat and chemicals in combination with very long retention times [13].

Density difference between the liquids is the basis of gravity settling. Density of water is usually greater than the density of oil. The water settles at the bottom of the cyclone and the oil floats on the water and will float over the top of the cyclone. Thus the water can be drained from the bottom of the separator and led to inject to the formation.

\subsubsection{Viscosity}

The higher the viscosities of the crude oil the lower the separation efficiency. High viscosity can be both natural and created in the process where emulsions can increase the viscosity up to several hundred centipoises. The water cut always has an influence on the viscosity. Being exposed to shear in valves or other restrictions the volume of water phase in the emulsion increases, which leads to increase in the viscosity. The smaller the droplets, the more stable is the emulsion and therefore the higher the viscosity. Droplet size distribution is influenced by the effectiveness of the chemical demulsifier. When the flow system is in turbulent state, the only practical means to estimate for droplet size is to 
assume it remains constant for a given demulsifier treatment program. That leaves viscosity as a sole variable controlling the separation rate. The viscosity of an oil-water

emulsion is a function of temperature and pressure. Using heat to reduce the viscosity and adding chemicals to de-stabilize the particles is not sufficient when settling force is very low $[13,16]$.

\subsubsection{Demulsifiers}

Demulsifiers have a significant influence on the performance of separators since the emulsion must be broken before gravity separation can take place. In an oil-water emulsion, there is a stable film at the oil-water interface, which keeps the tiny water droplets in the emulsified state.

Injected chemical is mixed and dissolved in the oil phase and then migrates to the interface to form a stable film. When the film is sufficiently weakened the water droplet can coalesce through random movement, the tiny droplets can collide with each other and coalesce to a form sufficiently large droplets for gravity settling. Efficient separation can take place when the droplet diameter is around $150 \mu$. Without effective demulsification water droplets may not coalesce rapidly enough to be separated in a reasonable sized vessel [16].

\subsubsection{Enforced Separation of Water from Oil}

Emulsions and high viscosity and/or small density difference between oil and water can cause the settling velocity to be so slow that efficient separation cannot take place in reasonable-sized gravity-based equipment. According to Stokes Law, the gravitational force is another factor that influences settling velocity. By replacing nature's gravity with centrifugal force this factor can be increased by several thousand-fold. The equation for the settling velocity is given as: [13]

$v_{c}=\frac{\mathrm{d}_{\mathrm{p}}^{2}\left(\rho_{\mathrm{w}}-\rho_{\mathrm{o}}\right)}{18 \mu} \mathrm{r} \varpi^{2}$

Where:

$$
\mathrm{v}_{\mathrm{c}}=\text { Centrifugal settling velocity }(\mathrm{m} / \mathrm{s}) \text {, }
$$


$\mathrm{r}=$ Radius of separation equipment $(\mathrm{m})$,

$\omega=$ Angular velocity $(1 / \mathrm{s})$

$\mathrm{d}_{\mathrm{p}}=$ Droplet diameter, $\mathrm{m}$

$\mu_{\mathrm{c}}=$ Viscosity of continuous phase, $\mathrm{kg} / \mathrm{ms}$

$\rho_{\mathrm{o}}=$ Density of oil phase, $\mathrm{kg} / \mathrm{m}^{3}$

$\rho_{\mathrm{w}}=$ Density of water phase, $\mathrm{kg} / \mathrm{m}^{3}$

Centrifugal force is utilized in equipment, such as decanters, centrifuges, or separators.

\subsubsection{Settling Velocity}

Separation velocity of a droplet from a continuous phase depends on the difference in gravity of the two phases, viscosity of continuous phase, and the droplet size and shape as known in the Stokes law (Equation 5).

In a horizontal separator the main body of the fluid flows horizontally from the inlet of the vessel to the outlet. Water droplets will have a projectile flow path down toward the interface. In physical terms the oil is continuous phase flowing from the oil-water interface at the inlet end of the vessel upward toward the overflow weir, while water droplets move opposite to this velocity toward the interface. The water droplets' vertical rate of descent is called terminal velocity and is defined by Stoke's Law. Water removal becomes possible when the upward velocity of the oil is less than the downward velocity of the water droplets [18].

\subsubsection{Droplet Diameter}

The recommended design droplet diameter to use in Equation 4 is $150 \mu \mathrm{m}$. This is well below the sizes encountered in gravity settler feeds. For instance, the droplet diameter in the settler is normally in 500 to $5000 \mu \mathrm{m}$ range. And the droplet size in turbulent flow is in the range of 200 to $10,000 \mu \mathrm{m}$. The mean droplet size is normally over $1000 \mu \mathrm{m}$, and very few fluids have droplet sizes under $500 \mu \mathrm{m}$ in diameter.

One would expect to use a design droplet diameter above $300 \mu \mathrm{m}$. However, due to inadequacies of the design equation, the gravity settlers sized for droplets over $300 \mu \mathrm{m}$ 
are usually too small to work well. Successful settlers have been designed using droplet diameters ranging from $50 \mu \mathrm{m}(0.00017 \mathrm{ft})$ to $300 \mu \mathrm{m}(0.001 \mathrm{ft})$. The most popular choice is $150 \mu \mathrm{m}(0.0005 \mathrm{ft})$. This is the size used in the API Design Method for designing gravity settlers [18].

\subsubsection{Over flow Rate}

Mathematically the overflow velocity is equal to the volumetric flow rate divided by the average horizontal area of the settler. The gravity settler is sized on the basis that velocity of the continuous phase must be less than the settling velocity of the droplets of dispersed phase. Plug flow is assumed. The velocity of continuous phase is calculated using the area of the interface as:

$v_{c}=\frac{\mathrm{Q}_{\mathrm{c}}}{\mathrm{A}_{\mathrm{I}}}<\mathrm{Vd}$

$\mathrm{v}_{\mathrm{c}}=$ Velocity of continuous phase, $\mathrm{m} / \mathrm{s}$

$\mathrm{v}_{\mathrm{d}}=$ Settling velocity of the dispersed phase, $\mathrm{m} / \mathrm{s}$

$\mathrm{Q}_{\mathrm{c}}=$ Continuous phase volumetric flow rate, $\mathrm{m}^{3} / \mathrm{s}$

$\mathrm{A}_{\mathrm{I}}=$ Area of interface, $\mathrm{m}^{2}$

It is required to identify which phase is continuous and which phase is dispersed. A correlation is presented for predicting dispersed phase. The correlation can be approximated using Equation 8 and the criteria given in Table 2:

$$
\begin{gathered}
\theta=\frac{\mathrm{Q}_{1}}{\mathrm{Q}_{\mathrm{h}}}\left(\frac{\rho_{l} \mu_{h}}{\rho_{H} \mu_{1}}\right)^{0.3} \\
\theta=\text { Factor for estimation of continuous phase } \\
\mathrm{Q}_{1}=\text { Light liquid volumetric flow, } \mathrm{m}^{3} / \mathrm{s} \\
\mathrm{Q}_{\mathrm{h}}=\text { Heavy liquid volumetric flow, } \mathrm{m}^{3} / \mathrm{s} \\
\rho_{1}=\text { Density of light liquid, } \mathrm{kg} / \mathrm{m}^{3} \\
\rho_{\mathrm{h}}=\text { Density of heavy liquid, } \mathrm{kg} / \mathrm{m}^{3} \\
\mu_{\mathrm{h}}=\text { Viscosity of heavy phase, } \mathrm{cp} \\
\mu_{1}=\text { Viscosity of light phase, } \mathrm{cp}
\end{gathered}
$$


Table 2: Dispersion discriminant [10]

\begin{tabular}{|l|l|}
\hline \multicolumn{1}{|c|}{$\theta$, factor } & Result \\
\hline$<0.3$ & Light phase always dispersed \\
\hline $0.3-0.5$ & Light phase probably dispersed \\
\hline $0.5-2.0$ & Phase inversion probable, design for worst case \\
\hline $2.0-3.3$ & Heavy phase probably dispersed \\
\hline$>3.3$ & Heavy phase always dispersed \\
\hline
\end{tabular}

\subsubsection{Dispersion Disengagement in a Gravity Settler}

The gravity settlers are designed to accept an inlet stream containing a volumetric fraction of (hold-up) contained in droplets and to produce fully separated outlet streams. If the gravity settler horizontal area is large and the dispersed phase travel rate is comparatively slow there exists two clear layers, at the interface incoming feed droplets coalesce immediately. If the dispersed phase feed is increased, a dispersion band will build up as indicated in Figure 3.3 If the feed rate is sufficiently high, two distinct layers can be separated within the dispersion band. $[19,20]$

The upper and lower borders of the dispersion band are not equivalent, since at one border (the lower one in the Figure 3.3, where the heavy phase is assumed to be dispersed) coalescence of droplets with their separated homogeneous phase is occurring; while at the other border there is no coalescence. Near the coalescing interface the droplets are large and form a close-packed zone where the hold-up of droplets is high and may approach unity. While in the adjacent sedimenting zone $[19,20]$ the droplets are less closely packed (the hold-up of the droplets is similar to the feed stream) and are more free to move relative to each other. The sedimenting interface differs from disengagement interface since there is no change in bulk phase. This sedimenting interface can be thought of as the upper surface of a liquid-fluidized bed, in which each droplet is sufficiently small to be supported by the up-flow of continuous phase but is too large to be carried upwards into the back, continuous phase. In the sedimenting zone the droplets 
grow in size by inter-droplet coalescence until they are large enough to fall to the closebacked zone.

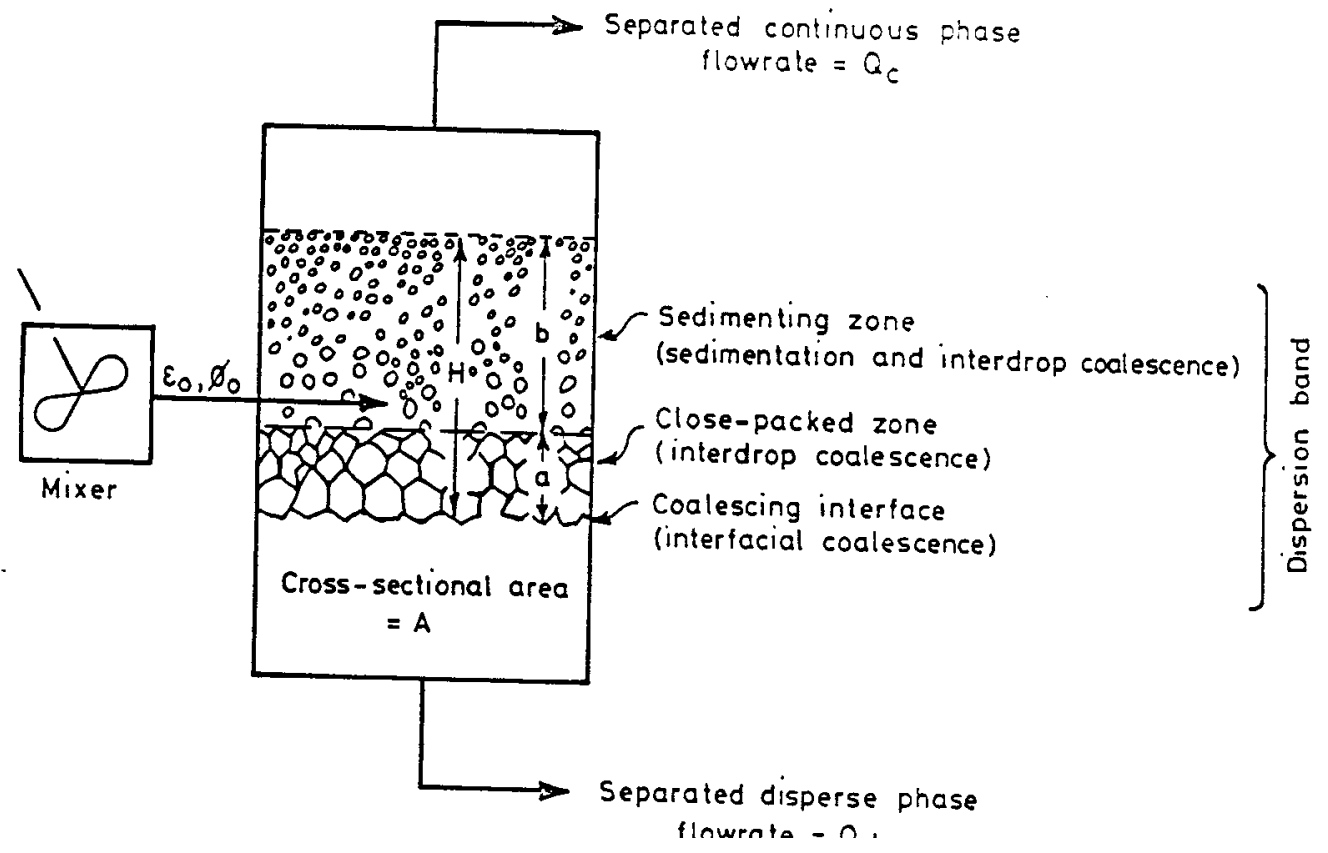

Figure 3.3: Disengagement of continuous settler [3]

In gravity settlers, horizontal movement is superimposed on vertical velocities.

Horizontal movement is more random in the sedimenting zone, when movement of droplets in the close-packed zone is mostly restricted to a plug-flow progression downwards towards the coalescence interface and horizontally towards the outlet. If the dispersion is fed into a sedimenting zone of smaller dispersed phase hold-up it will initially tend to gravitate towards the boundary of the sedimenting and close-packed zone, forming a chimney.

Sedimenting zone ensures that the superficial velocity of the continuous phase does not exceed the terminal velocity of the feed droplets. The dispersion band height will always stabilize at the steady value. If the feed point( Figure 3.4) were raised further there would be a tendency for the top of the sedimenting zone to rise to the same level. In any case it is recommended for practice to design for a feed inlet at the zone boundary or near the coalescence interface if the zones are not well defined. 


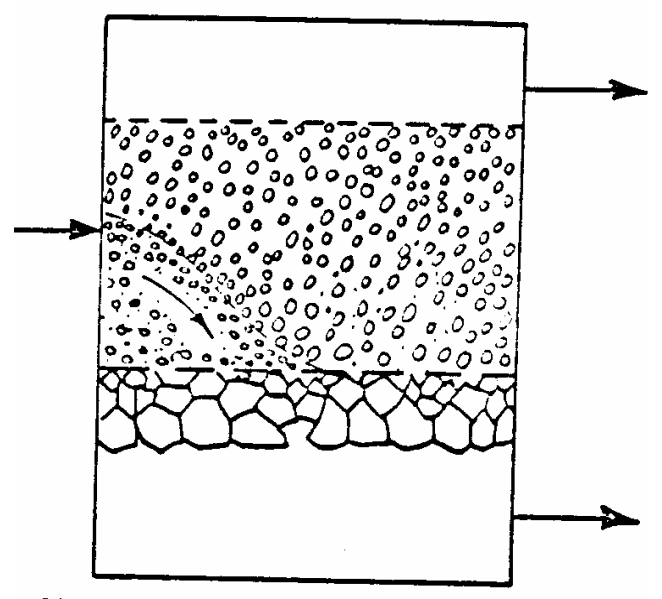

Figure 3.4: Chimneying of feed dispersion in a deep settler

\subsubsection{Coalescence}

The process of coalescence is when two droplets or a droplet and its homogeneous phase approach each other more and more closely until the film of continuous phase between them ruptures and coalescence occurs. The speed of approach and coalescence time is determined by the rate at which the fluid in the intervening film can escape after film rupture when the new droplet forms instantaneously. If the approach velocity of two droplets is high they may rebound without coalescing due to a high level of turbulence in dispersion. Time required for those collected droplets to cross the interface is often the limiting factor of the size of the gravity settler. If the phases are not pure components, the droplets do not readily combine in the continuous phase and most of them remain discrete until they reach the interface. When a droplet reaches the interface, it settles on the interface under the influence of gravity.

There is no simple equation to predict the time required for a droplet to cross the interface. Typical values range from a fraction of a second up to 2 or 3 minutes. The net effect of various parameters on coalescence time $(\tau)$ is summarized in Table 3 $[16,18]$. 
Table 3: Factors affecting coalescence time

\begin{tabular}{|l|l|}
\hline Parameters & Effect on $\tau$ \\
\hline Droplet size increase & Decrease \\
\hline Velocity of impact increase ( turbulence) & Increase \\
\hline Force (gravitational force) increase & Decrease \\
\hline Electrostatic field increase & Decrease \\
\hline Viscosity of droplet increase & Increase \\
\hline Viscosity of continuous phase increase & Increase \\
\hline
\end{tabular}

\subsubsection{Turbulence}

In a horizontal gravity settler, the continuous phase is flowing perpendicular to the settling of droplets. This movement creates turbulence that interferes with the settling process. If the cross flow is fully laminar, there would be no problem, but this is usually impractical. The Reynolds number expresses the degree of turbulence. The following guidelines in Table 4 are recommended for gravity settlers. [18].

Table 4: Guide lines for successful separators

\begin{tabular}{|l|l|}
\hline $\mathbf{N}_{\mathbf{R e}}$ & Results \\
\hline$<5000$ & Little problem \\
\hline $5000-20,000$ & Some hindrance \\
\hline $20,000-50,000$ & Major problem may exist \\
\hline Above 50,000 & Expect poor separation \\
\hline
\end{tabular}




\section{CHAPTER IV: HYDRO-CYCLONE PROCESS MODELING}

The preprocessing software or Gambit is used to build geometry and generate an unstructured mesh around the body of the hydro-cyclone, which could then be analyzed using CFD. Figure 4.1 shows the CFD modeling structure. The modeling structure is used to define modeling goals and identify its modeling domain, then create grid cells and ensure the quality of the grid.

Numerical model is set up, the solution is monitored and finally the results are examined to consider revision of the model if needed. The creation of liquid-liquid hydro-cyclone model consists of set of integrated cylindrical and conical sections for Fluent analysis. Before meshing could be applied the geometry should be checked and cleaned if needed [14].

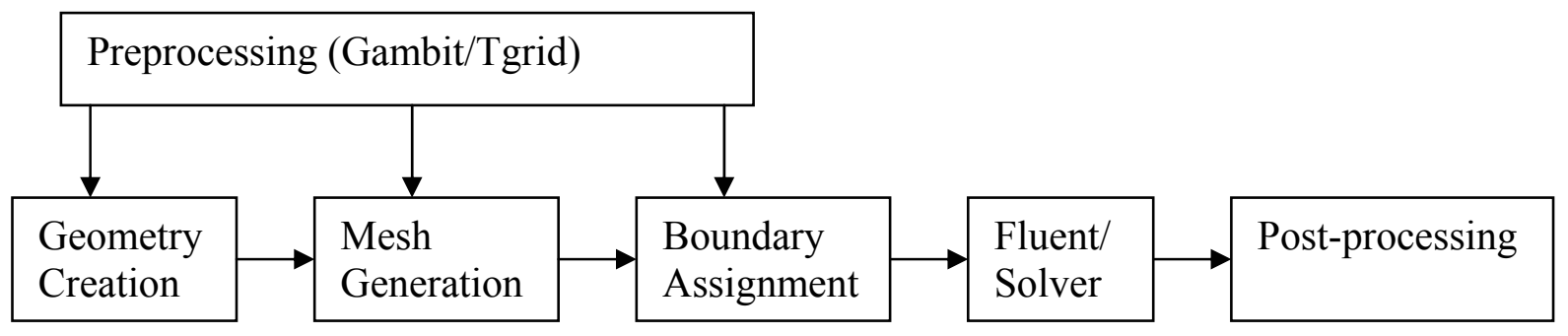

Figure 4.1: CFD Modeling Structure

The steps of preprocessing procedure used for modeling hydro-cyclone behavior with CFD are:

1. Create Hydro-cyclone geometry (integrate cylindrical and cone sections).

2. Generate mesh (faces, edges and cells) using TGrid.

3. Examine mesh quality.

4. Assign boundary zones (inlet, outlet and walls).

5. Set up numerical solution.

6. Analyze and modify solution if needed (post-processing). 


\subsection{HYDRO-CYCLONE GEOMETRY}

The Colman and Thaw [3] design for a cyclone has four sections: inlet chamber, reducing section, tapered section and tail pipe. Inlet chamber and reducing section are designed to achieve higher tangential acceleration of fluid while reducing pressure drop and shear stress to an acceptable level. The reducing section has to minimize droplet breakup, the leading reduction of separation efficiency. Tapered section is where most of separation is achieved. The low angle of this part keeps swirl intensity high.

The last part (tailpipe) is where the smallest oil droplets immigrate to reverse flow core at the exit. Another important parameter in hydro-cyclone geometry is the inlet configuration. Most often rectangular and circular, single and twin inlets have been used The main idea is to inject the fluid with higher tangential velocity, avoiding the rupture of the droplet.

The overflow outlet section of the hydro-cyclone has a very small diameter and it plays a major role in the split ratio-defined relationship between the overflow and inlet flow rate equation. [2,6]. The cyclone geometry used in the first part of the study is given in Figure 4.2 .

\subsection{MESH GENERATION}

For a given boundary mesh with some two dimensional (2D) quadrilateral or three dimensional (3D) hexahedral cells, TGrid (preprocessor) generates an unstructured triangular or tetrahedral (hybrid) grid.

In 2D, boundary mesh consists of nodes and straight edges, whereas in 3D mesh consists of nodes and triangular and or quadrilateral faces. Boundary mesh file can be obtained from Gambit. This file can be read into the solver where solution process and postprocessing can occur. The basic steps of grid generation are: 


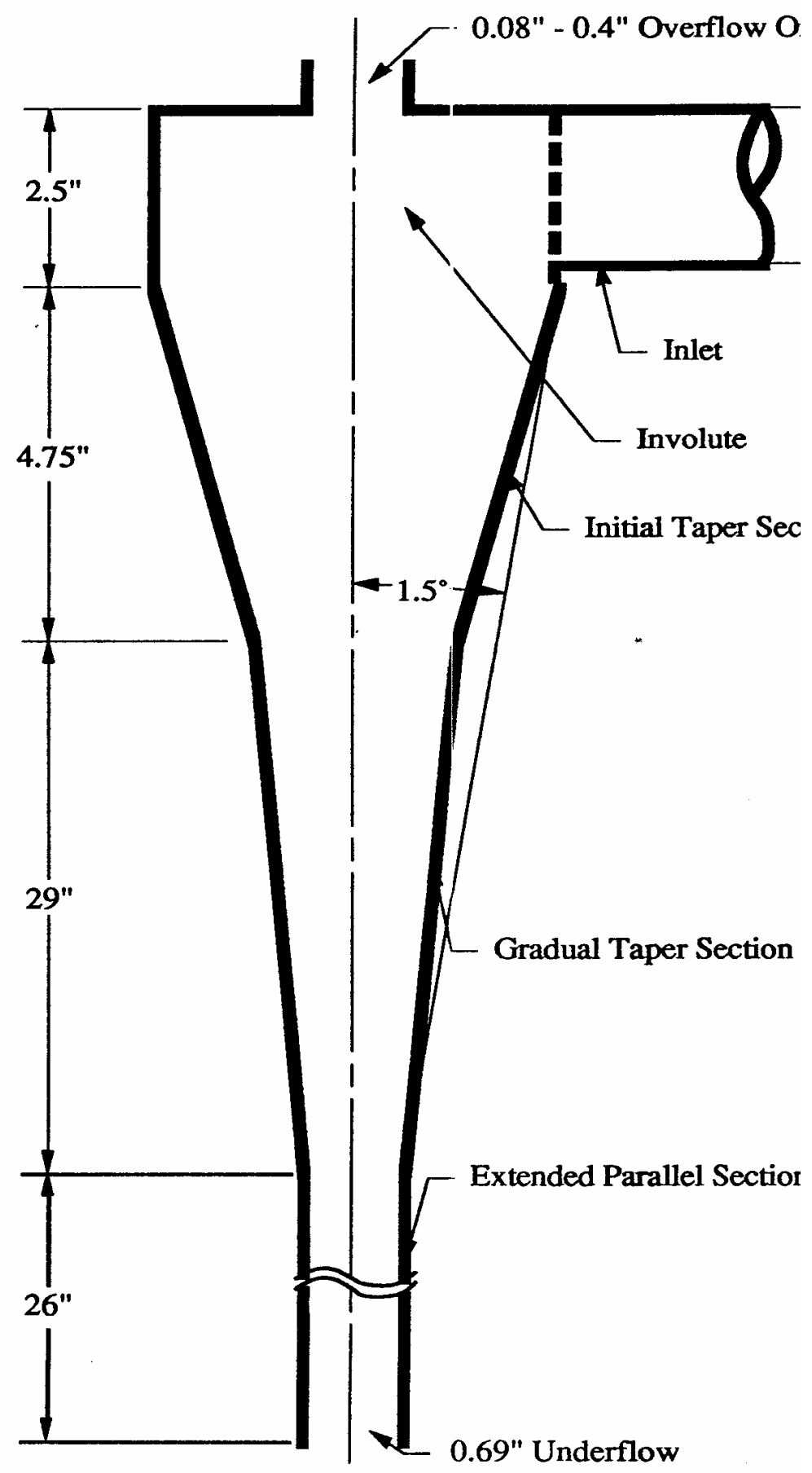

Figure 4.2: Hydro-cyclone Dimensions [3] 
1. Read a boundary mesh file containing some $2 \mathrm{D}$ quadrilateral or $3 \mathrm{D}$ hexahedral cells.

2. Examine boundary mesh for topological problems such as free edges and duplicate nodes. Once the boundary mesh is topologically correct, a 3D surface mesh can be checked for poor face quality. Many quality-related problems can be solved easily with edge swapping but more difficult problems may require direct manipulation of the faces and node.

3. Generate the volume mesh. We can perform this automatically or by proceeding through a series of steps. For hybrid grids we first generate any prism or pyramid and then generate triangular or tetrahedral volume cells. We can then extend the computational domain by generating more prisms, if desired. For grids containing only triangles and tetrahedrals, we can perform automatic mesh generation procedure or perform each step at a time.

4. Check the mesh problems or quality of mesh. We have to look carefully at the worst cells both for their quality and their location. The presence of degenerated cells will prevent us from obtaining solution and very poor cells in critical areas will cause serious accuracy and convergence problems. If bad cells cannot be removed or improved we need to generate a new mesh by modifying boundary mesh or using different mesh parameters.

5. Finally, we need to write the mesh to a new file for input to the solver.

Generating different grid systems depends on complexities of geometry and flow. Also, we need to know if we have enough computer memory, how many cells are required and how many models will be used (one-stage separation model or two-stage separation model).

For simple geometries, quad/hex mesh can provide higher quality solutions with fewer cells than compared to tre/tet mesh. For complex geometries, quad/hex shows no numerical advantage and one can save meshing effort by using a tri/tet mesh. 
Finally we need to choose solver and specify boundary types for inflow and outflow boundary [14]

\subsection{FLUENT MODELING OVERVIEW}

For given problems, it is desirable to select appropriate physical models such as turbulence and multiphase models. The solver allows the user to specify various parameters associated with the solution method to be used in calculations like space (2D or 3D) dimensionality of domain, time (steady or unsteady), porous formulation and the velocity formulation. Figure 4.3 presents Fluent modeling overview. The solver uses two numerical methods:

- Segregated solver

- Coupled solver

Using either method, Fluent will solve the governing integral equation for conversion of mass, momentum and energy (if needed) and other parameters such as turbulence and chemical species [14].

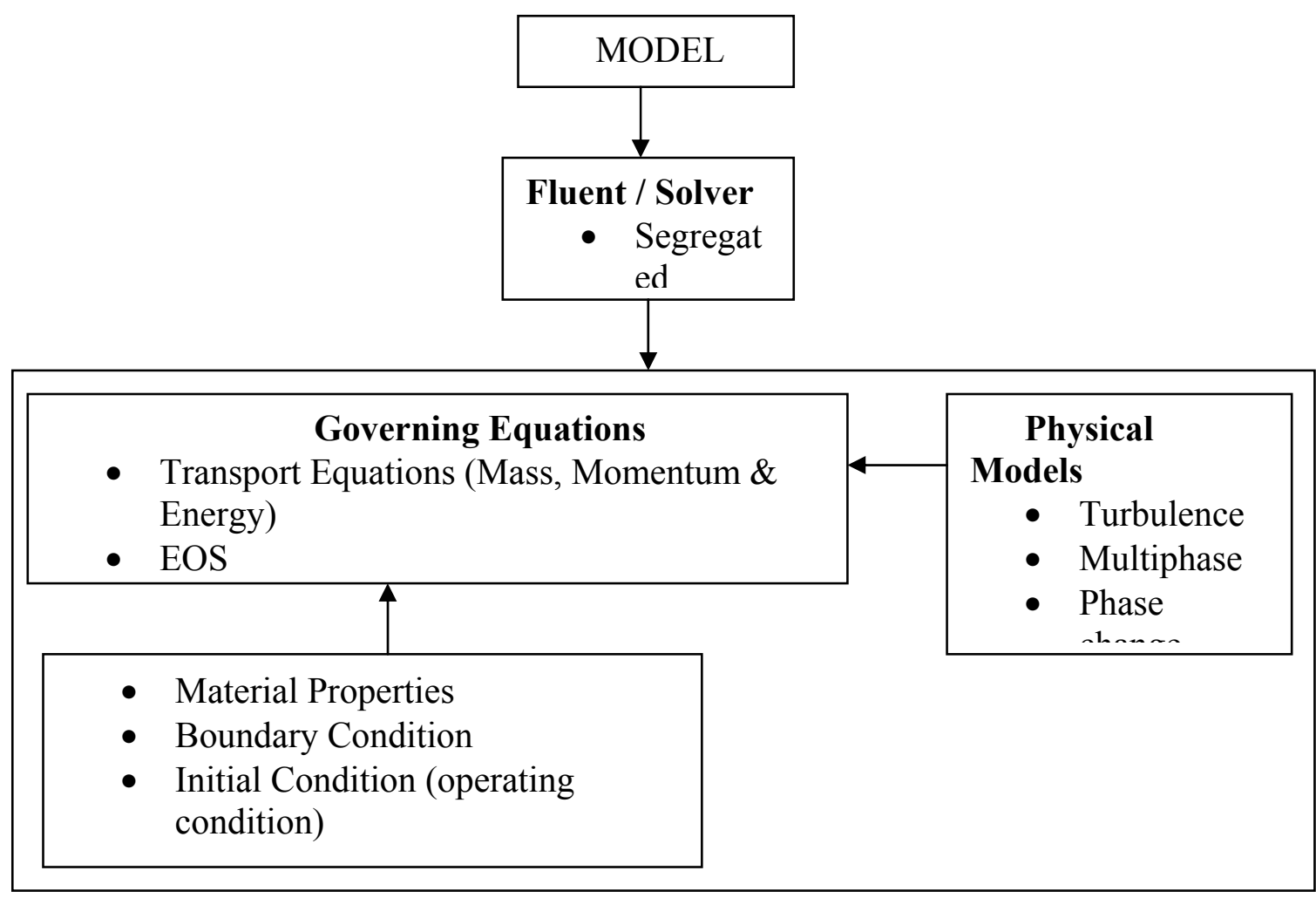

Figure 4.3: CFD Modeling Overview 
In both methods control-volume-based technique is used, which consists of:

- Division of the domain into cells using computational grid

- Integration of the governing equation of the individual control volumes to construct algebraic equations for unknowns such as velocity, pressure and other parameters.

The two numerical methods employ the similar finite volume process, but the approach used to solve discretized equations is different.

\subsection{SOLVER SELECTION}

Coupled solver (implicit) is recommended if strong interdependency exists between density, energy, momentum and species; for example, high-speed reaction compressible flow and finite rate reaction flows. In general segregated solver (explicit) is recommended over the coupled (implicit) solver for the following reasons:

- Time required for coupled solver runs roughly twice the time required for segregated solver.

- Coupled solver requires large memory compared to segregated solver

- Segregated solver is preferred because it provides flexibility in solution procedure.

\subsubsection{Segregated Solution Method}

The segregated solution method is the solution algorithm used in this study. In this approach the governing equations are solved sequentially because equations are nonlinear and several iterations of the solution loop must be performed before the converged solution is obtained [14].

Each-iteration consists of procedures presented in Figure 4.4 as outlined below.

1. Fluid properties are updated, based on the current solution. If the calculation has just begun, the fluid properties will be updated based on operating condition or initialized solution.

2. The momentum equations are each solved in turn using current values for pressure and face mass flow rate, in order to update the velocity field. 
3. Since the velocities obtained in Step 2 may not satisfy the continuity equation the pressure correction is derived from the continuity equation and the linearized momentum equations. This pressure correction equation is then solved to obtain the necessary corrections to the pressure and velocity fields and the face mass flow rate such that continuity is satisfied.

4. Appropriate equations for scalars such as turbulence and energy are solved using the previously updated values of the other variables

5. When inter phase coupling is to be included, the source terms in the appropriate continuous phase equations may be updated with a discrete phase trajectory calculation.

6. A check for convergence of the equation set is made.

These steps are continued until the convergence criteria are met [14].

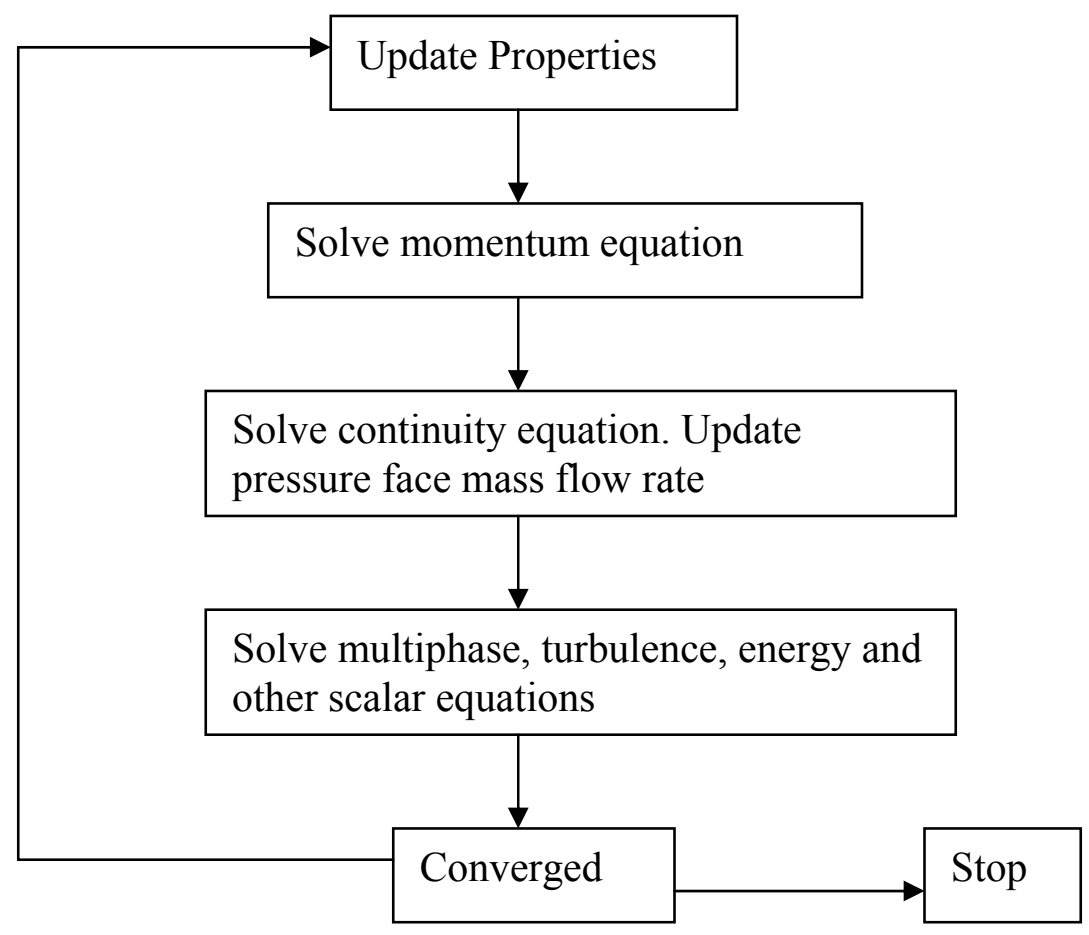

Figure 4.4: Procedure for Segregated Solution Method 


\subsubsection{Modeling multiphase flow}

Multiphase is a simultaneous flow of more than one flow phase. It is generally liquid. It has materials with different chemical properties but the same phase, such as water or oil, and the fluids are defined as primary phase or continuous phase (dominant phase) and secondary phase (dispersed within continuous phase). In order to choose a multiphase model for the hydro-cyclone we need to understand the following conditions:

1. Multiphase flow regime: Many regimes are possible, such as slug flow (large bubble in continuous liquid), droplet flow and free surface flow ( immiscible fluids separated by a clearly defined interface)

2. Volume loading: This property can be dilute or dense (volume fraction of dispersed phase). It is defined as:

Volume Fraction $=\frac{\text { Volume of the phase in a cell }(\text { domain })}{\text { Volume of the cell }(\text { domain })}$

3. Stokes Number $(\mathbf{S t})$ : It is the ratio of particle relaxation time $\left(\tau_{d}\right)$ to problem characteristic time $\left(t_{c}\right)$. Stokes number provides selecting the most appropriate model. It is given as:

$$
S t=\tau_{d} / t_{c}
$$

4. Turbulence or Laminar flow: Reynolds Number determines the flow regime. After determination of characteristics of the fluids we can choose an appropriate model based on the above-mentioned conditions. The following multiphase modules are available in Fluent. [14]:

1. Discrete Phase Module (DPM)

2. Mixture Model

3. Eulerian Multiphase Flow Model

4. Volume of Fluid Model (VOF) 


\subsubsection{Discrete Phase Model (DPM)}

Each trajectory represents a group of particles of the same initial properties or singlephase with multi species. Table 5 shows the conditions to exist in order to apply this model. Particle-particle interactions are neglected in the DPM model. This model can be applied to cyclones and spray dryers.

Table 5: Applicability of DSP Model

\begin{tabular}{|l|l|}
\hline Flow regime & $\begin{array}{l}\text { Bubbly flow, droplet flow and particle-laden } \\
\text { flow }\end{array}$ \\
\hline Volume loading & Must be dilute (volume fraction $<12 \%)$ \\
\hline Particular loading & Low to moderate \\
\hline Stokes Number & All range of Stokes number \\
\hline Turbulence modeling & Weak to strong coupling between phases \\
\hline
\end{tabular}

\subsubsection{The Mixture Module}

The mixture model is a simplified Eulerian model based on the small Stokes number. This model solves the mixture momentum equation and creates the relative velocity of lighter phase (dispersed phase). Turbulence, flow, slip velocity, volume of each phase and energy equations are solved if needed. When the conditions presented in Table 6 exist, then it is desirable to apply the mixture module. This model can be applied to bubble column reactors, hydro-cyclones and gas sparging.

\section{Table 6: Applicability of Mixture Model}

\begin{tabular}{|l|l|}
\hline Flow regime & Slurry, Bubbly and droplet flow \\
\hline Volume loading & Dilute to moderately dense \\
\hline Particular loading & Low to moderate \\
\hline Stokes Number & Stokes Number $<<1$ \\
\hline Turbulence modeling & Weak coupling between phases \\
\hline
\end{tabular}




\subsubsection{The Volume of Fluid Model (VOF)}

This model can track the position of interface between two immiscible liquids and can be applied to the single momentum equation to solve velocity field shared by different phases. Turbulence and energy equations are also shared by all phases. When conditions listed in Table 7 are present, the VOF model can be applied. This model can be applied to large slug flows, offshore oil-tank sloshing, boiling and coating. [14]

Table 7: Applicability of VOF Model

\begin{tabular}{|l|l|}
\hline Flow regime & Slug flow \\
\hline Volume loading & Dilute to dense \\
\hline Particular loading & Low to high \\
\hline Stokes Number & All ranges of Stokes Number \\
\hline Turbulence modeling & Weak to modern coupling between phases \\
\hline
\end{tabular}

\subsubsection{Material Types and Properties}

Physical model may require inclusion of additional material and dictate which properties need to be defined. Material properties are defined in Fluent material panel.

Fluid properties of water and oil (immiscible liquid) are defined and model is setup with physical properties in trials relevant to the scope of the problem. These properties may include the following: [14]

- Density and/or molecular weights

- Viscosity

- Heat capacity

- Thermal conductivity

- Mass diffusion coefficients

- Standard state enthalpies

- Kinetic theory parameters

The assumed reservoir properties may not be temperature-dependent (isothermal) but can be composition-dependent. The Fluent will guide the user for properties that need to be 
defined for the active physical models. If any property defined requires the energy equation to be solved, Fluent will automatically activate the energy equation. Then the thermal boundary conditions and other parameters are to be defined.

\subsubsection{Operating Pressure}

To avoid runoff error Fluent will subtract atmospheric pressure from the absolute pressure and use resulting gauge pressure. All pressures computed or reported by Fluent are gauge pressures [14]. Equation 11 gives the relationship between gauge and absolute pressure.

$$
P_{a b s}=P_{\text {gauge }}+P_{a t m}
$$

\subsubsection{Setting Operating Pressure}

The procedure for selecting appropriate operating pressure is based on the Mach-number regime of the flow and density relationship. For example, if a constant density is selected for an incompressible flow calculation, operating pressure is not needed; or if Mach number is less than 0.1 , the mean flow pressure is selected as the operating pressure. The criteria for selecting operating pressure are given in Table 8.

Table 8: Recommended procedure for selecting operating pressure

\begin{tabular}{|l|l|l|}
\hline Density Relationship & Mach Number Regime & Operating Pressure \\
\hline Ideal Gas Law & $\mathbf{M}>0.1$ & 0 or $\approx$ Mean Flow Pressure \\
\hline & $\mathbf{M}<0.1$ & $\approx$ Mean Flow Pressure \\
\hline Profile Function of Temperature & Incompressible & not used \\
\hline Constant & Incompressible & not used \\
\hline Incompressible Ideal Gas Law & Incompressible & $\approx$ Mean Flow Pressure \\
\hline
\end{tabular}




\subsubsection{Boundary Condition}

The information regarding the boundaries is defined in terms of mass flow rate, momentum and volume fraction. Also, the location of the boundaries (inlet, outlet and wall) is determined and information is provided for each boundary. The input (data) required at the boundary depends upon the type of boundary condition and selected physical model. Poorly defined boundary conditions can have a significant impact on solution. The boundaries available in Fluent are classified as follow:

- Flow inlet boundaries: pressure, velocity or mass flow.

- Flow outlet boundaries: pressure or mass flow.

- Wall boundary: wall, symmetry, periodic, axis.

- Internal cell zones (interior): fluid.

- Internal face boundaries: wall and interior.

\subsubsection{Inlet velocity}

Inlet velocity depends on mass flow rate and inlet geometry. In order to specify inlet velocity for the mixture the followings are used:

1. Turbulence specification methods. This method has the following options:

- Intensity and hydraulic diameter.

- Intensity and viscosity ratio.

- Intensity and length scale.

- K-epsilon.

2. Assign inlet velocity for water phase as well oil phase by one of the following criteria as:

- Magnitude, normal to the boundary, is specified.

- Components are specified.

- Magnitude and direction are specified.

- Volume fraction of dispersed phase (oil) is specified. 
The program needs to know the method used to input the turbulence parameters. In case intensity and hydraulic diameter method is selected the following equations are used to estimate turbulence parameters.

$$
\begin{aligned}
& \text { Turbulence Intensity }(\mathrm{I})=\frac{v^{\prime}}{v_{\text {avrage }}}=0.1 .6\left(\mathrm{Re}_{D H}\right)^{-1 / 8} \\
& \text { Hydraulic Diameter }\left(\mathrm{D}_{\mathrm{H}}\right)=\text { pipe }- \text { diameter } \rightarrow \frac{4 \pi r^{2}}{2 \pi r}
\end{aligned}
$$

\subsubsection{Outlet pressure}

In the mixture model, outlet pressures are specified for the mixture and secondary phase (oil). There are no conditions set for water phase (primary phase). The input value of the turbulence conditions at the pressure outlets will be applied only if flow enters the domain through this boundary. Often it is important to set reasonable values for this downstream scalar value in case reverse flow occurs at some point during iterations.

The procedures to select boundary conditions for outlet pressure of mixture phase are:

1. Select pressure for outlets.

2. Select inlet velocity of oil and water (same value).

3. Select Backflow turbulence intensity.

4. Select Backflow turbulence length scale.

5. Select backflow volume fraction for the oil phase

\subsubsection{Outflow}

Pressure and velocity specifications are not required for outflow boundary. Mass balance correction is applied at boundary. This specification is not used with a pressure inlet boundary specification and it is used when velocity is specified at the inlet boundary 
condition. When backflow is expected for final solution the outflow specification is not used.

\subsection{SOLUTION ALGORITHM}

The best technique for speeding convergence is to tackle the problem one step at a time. CFD automatically solves each equation that applies to the selected problem. The mixture and volume of fluid models solve the transport equation for volume fraction, momentum equation, continuity equation, slip velocity and draft velocity.

\subsubsection{Continuity Equation for Mixture Model}

The equation for continuity in the mixture model is given for the following equation:

$$
\begin{aligned}
& \frac{\partial}{\partial t}\left(\rho_{m}\right)+\nabla \cdot\left(\rho_{m} \bar{v}_{m}\right)=0 \\
& \rho_{m}=\sum_{k=1}^{n} \alpha_{k} \rho_{k} \\
& \bar{v}_{m}=\frac{\sum_{k=1}^{n} \alpha_{k} \rho_{k} \bar{v}_{k}}{\rho_{m}}
\end{aligned}
$$

$$
\begin{aligned}
& \text { where } \rho_{m}=\text { Density of mixture } \\
& \qquad \begin{aligned}
\alpha_{k} & =\text { Volume fraction of phase } \mathrm{k} . \\
\bar{v}_{m} & =\text { The mass average velocity. }
\end{aligned}
\end{aligned}
$$

\subsubsection{Momentum Equation}

The momentum equation for the mixture model is developed by adding the individual momentum equations for both oil and water. It can be expressed as: 


$$
\begin{gathered}
\frac{\partial}{\partial t}\left(\rho_{m} \bar{v}_{m}\right)+\nabla *\left(p m v_{m}-\overline{v_{m}}\right)=-\nabla p+\nabla \cdot *\left[\mu_{m}\left(\nabla \overline{v_{m}}+\nabla v_{m}^{-T}\right)\right]+ \\
\rho m g+\bar{F}+\nabla \cdot\left(\sum_{k=1}^{n} \alpha_{k} \rho_{k} v_{d r, k}^{-} v_{d r, k}^{-}\right)
\end{gathered}
$$

Where

$$
\begin{aligned}
& \mathrm{n}=\text { Number of phases } \\
& \mathrm{F}=\mathrm{A} \text { body force } \\
& v_{d r, k}^{-}=\text {The drift velocity of secondary phase given as : } \\
& \bar{v}_{d r, k}^{-}=\bar{v}_{k}^{-}-\bar{v}_{m}
\end{aligned}
$$

and $\mu_{m}$ is the viscosity of mixture represented by:

$$
\mu_{m}=\sum_{k=1}^{n} \alpha_{k} \mu_{k}
$$

\subsubsection{Volume Fraction of Secondary Phase}

After solving continuity equation for secondary phase the volume fraction of secondary phase can be obtained:

$$
\frac{\partial}{\partial t}\left(\alpha_{p} \rho_{p}\right)=\nabla .\left(\alpha_{p} \rho_{p} v_{d r, p}^{-}\right)+\sum_{q=1}^{n}\left(\bar{m}_{q p}^{-}-m_{p q}^{-}\right)
$$

\subsubsection{Slip Velocity and Drift Velocity}

Slip velocity is also referred to as the velocity of oil "p" (secondary phase) relative to velocity of water "k" (primary phase). CFD mixture model uses a slip formulation or interaction between the oil phase and water phase. Following Manninen et al the slip velocity is given [14] as: 
$\bar{v}_{p q}=\frac{\tau_{p}}{f_{d r a g}} \frac{\left(\rho_{\mathrm{p}}-\rho_{m}\right)}{\rho_{p}} \bar{a}$

where: $\tau_{p}$ is particle relaxation time defined by :

$$
\tau_{p}=\frac{\rho_{p} d_{p}^{2}}{18 \mu_{q}}
$$

$d$ is the diameter of the particle in oil phase (secondary phase) and $\bar{a}$ is oil phase particle accelaration and $f_{\text {drag }}$ are given by Schiller and Naumann as :

$$
\begin{aligned}
f_{\text {drag }}= \begin{cases}1+0.15 \mathrm{Re}^{0.687} & \mathrm{Re} \leq 1000 \\
0.0183 \mathrm{Re} & \mathrm{Re}>1000\end{cases} \\
-\bar{a}=\bar{g}-\left(v_{m}^{-} \cdot \nabla\right) v_{m}-\frac{\partial v_{m}}{\partial t}
\end{aligned}
$$




\subsection{SOLUTION PROCEDURE OVERVIEW}

Figure 4.5 summarizes the procedure used in model setup and parameters selection.

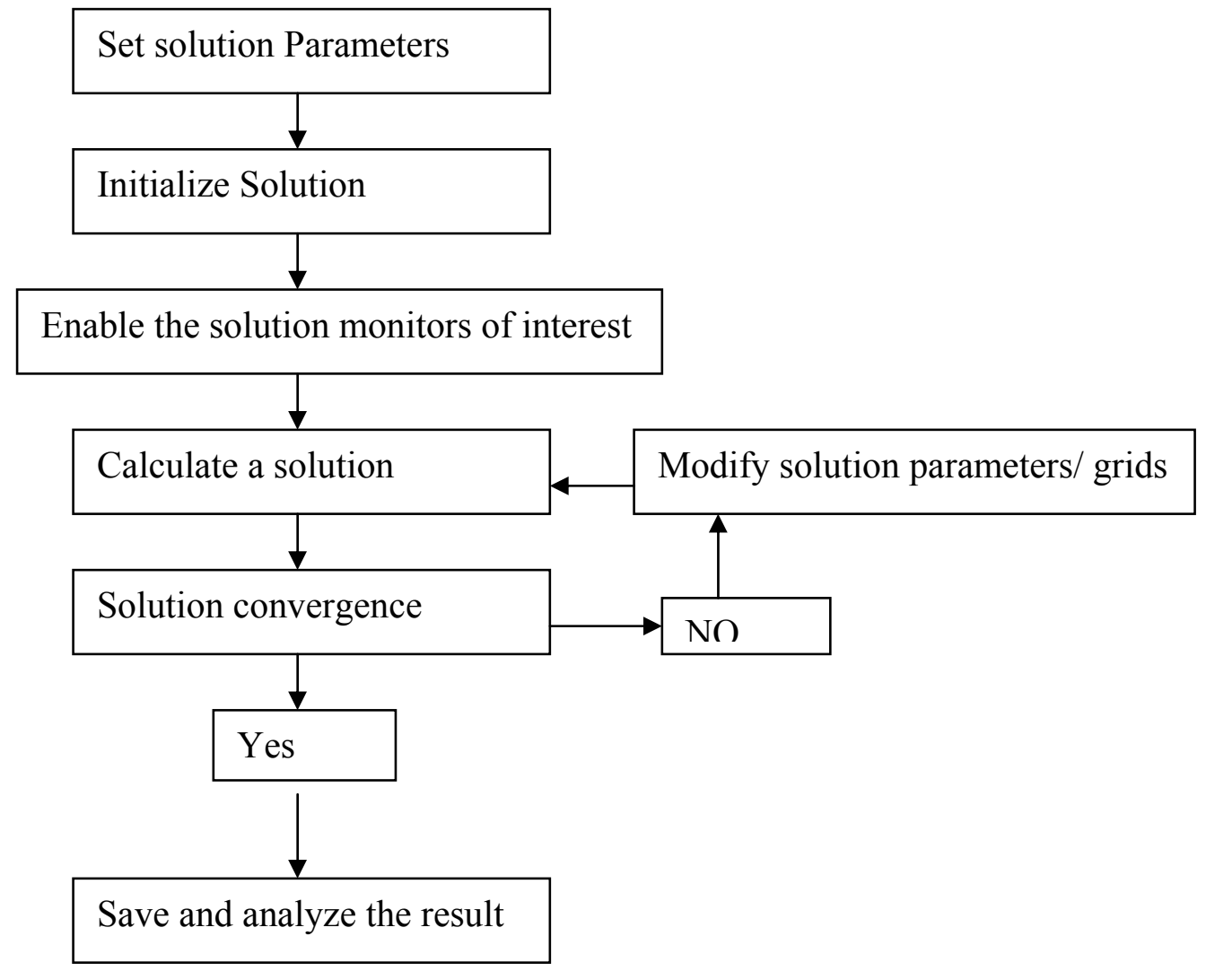

Figure 4.5: Solution Procedure 


\section{CHAPTER V: MODEL SETUP}

\subsection{PHYSICAL MODEL}

In this study, a 2.8 inch liquid-liquid hydro-cyclone model is used. The model consists of a set of integrated cylindrical and conical sections created with preprocessing software (Gambit). As shown on Table 9 the created dimensions of the mixture inlet section was 2 inches in diameter and 1.5 inch in length, oil outlet pipe was 1 inch in diameter and 1.5 inch in length. At the bottom of tapered section where most of separation is achieved a cone is used and connected to a water outlet pipe with 1.6 inch diameter and 6 inch length.

Table 9: Dimensions of Physical Model

\begin{tabular}{|l|l|l|l|}
\hline Section & Radius (inch) & Length (inch) & Shape \\
\hline Inlet chamber & 1.4 & 2.5 & Cylinder \\
\hline Mixture inlet & 1 & 1.5 & Cylinder \\
\hline Oil outlet & 0.5 & 1 & \\
\hline Tapered section & 1.4 & 6 & Cylinder \\
\hline Water outlet & 0.8 & 2 & Cone \\
\hline
\end{tabular}

Since a complex geometry was considered, hybrid mesh or tri/tet grid was generated in volume meshing and thousands of tetrahedral cells were created. The boundary types were specified as inlet velocity, outlet pressure and wall. Fluid was selected as a continuum and the resulting mesh was exported to the solver. The mesh file created with Fluent option 3ddp and case file was run and the grid was checked. Particular attention was paid to the reported minimum volume to make sure it was a positive number. Segregated solver was set up and the selection of mixture and volume of the fluid multiphase model was made after studying the characteristics of different parameters such as volume fraction, Stoke's number and turbulence. Dispersed (oil) and continuous phase (water) were also specified. Since incompressible flow (constant density) was used, the recommended procedure in Table 8 was used for setting operating pressure. The 
gravitational acceleration values were 0,0 , and $9.81 \mathrm{~m} / \mathrm{s}^{2}$ for $\mathrm{x}, \mathrm{y}$ and $\mathrm{z}$ directions, respectively.

The boundary conditions for flow rates ranged from $135 \mathrm{~m}^{3} / \mathrm{d}$ to $385 \mathrm{~m}^{3} / \mathrm{d}$. Fluid velocity specification method and turbulence specification method was used in the model.

Wall was assumed to be a stationary wall since hydro-cyclone doesn't have a rotating part. Back pressure was applied at hydro-cyclone underflow in order to force oil phase into the overflow outlet, otherwise, all the flow exits the underflow and no separation will occur. The discrete numerical solution algorithm was selected. Once iterations are completed and convergence was achieved, velocity, pressure and volume fraction profile were drawn and mass flow rate in both oil outlet and water outlet were studied and analyzed.

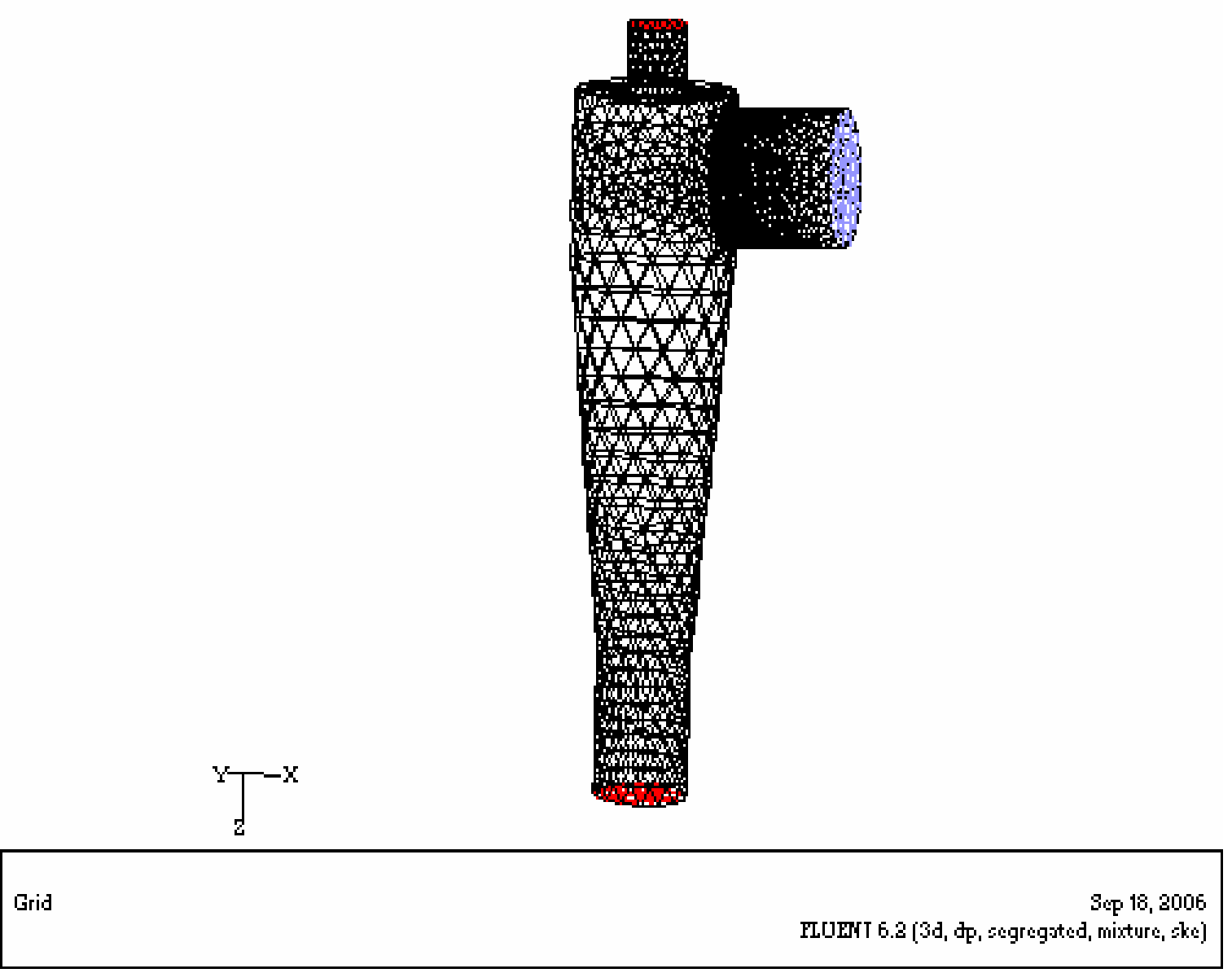

Figure 5.1: Created Grid 


\subsection{DEFINING MATERIALS}

After selecting the physical model for the cyclone separation problem such as solver, multiphase model and viscous model the material properties required for the active physical models were selected. We selected materials and their physical properties that are relevant to the scope of the problem. These properties include density or molecular weights, viscosity and API oil gravity. Reservoir temperature was assumed to be constant as $113^{0} \mathrm{~F}$ throughout the study. Solubility of gas was neglected since two phases (oilwater) were considered. The viscosity values were calculated using the Beal equation. Properties used as input to the Fluent are presented in Table 10.

The viscosity of oil phase $\left(\mu_{O D}\right)$ in cp is calculated with the following equation:

$\mu_{O D}=\left[0.32+\frac{1.8 e+7}{(A P I)^{4.53}}\right]\left(\frac{360}{T-260}\right)^{a}$

where :

$$
\begin{aligned}
& \mathrm{T}=\text { Reservoir Temperature }\left({ }^{0} \mathrm{R}\right) \\
& \mathrm{a}=10^{\left(0.43+\frac{8.33}{\mathrm{API}}\right)}
\end{aligned}
$$

Table 10: Material Properties used for this study

\begin{tabular}{|l|l|l|l|}
\hline${ }^{\mathbf{A}}$ API & Specific Gravity & Density, Kg/cm & Viscosity,cp \\
\hline 50 & 0.7796 & 778.815 & 1.2 \\
\hline 40 & 0.8251 & 824.227 & 1.3 \\
\hline 30 & 0.8762 & 875.263 & 8.25 \\
\hline 20 & 0.9340 & 933.036 & 62.24 \\
\hline 15 & 0.9659 & 964.881 & 328 \\
\hline
\end{tabular}




\section{CHAPTERVI: DISCUSSION OF RESULTS}

\subsection{MODEL VERIFICATION}

To test and verify this model, published field data from well VM-097, La Ventana field, was used prior to conducting runs. A 2.8 inch diameter liquid-liquid cyclone was used (see Table 9) with 25,000 tetrahedral cells. Segregated solver is selected for the multiphase mixture model and material properties selected are given in Table 10. Boundary condition was set with inlet velocity of $2.2 \mathrm{~m} / \mathrm{s}$ for both phases as an input, and oil volume fraction of $2.3 \%$ was selected for input. Underflow backpressure was set to be constant and static pressure of the oil outlet was adjusted gradually in order to force oil phase into the overflow outlet. The results for this run are shown in Table 11. Pressure, velocity, volume fraction and turbulence profiles obtained by the model for verification run are presented in Figures 6.1 through 6.4.

Based on the results of static pressure (Figure 6.1), there was a small pressure difference between water inlet and oil outlet. Water velocity profile for the outlet section yielded lower values compared to water velocity profile in oil outlet, due to acceleration forces or rotations acting on the inlet chamber.

Table 11: Well VM: production without and, with DOWS and CFD simulation result

\begin{tabular}{|l|c|c|c|}
\hline & $\begin{array}{l}\text { Without DOWS } \\
\text { installation }\end{array}$ & $\begin{array}{l}\text { With DOWS } \\
\text { installation }\end{array}$ & CFD Simulation \\
\hline Gross rate, $\mathrm{m}^{3} /$ day(STB/D) & $385(2420)$ & $385(2420)$ & $385(2420)$ \\
\hline Oil to surface, $\mathrm{m}^{3} /$ day(STB/D) & $8.855(55.7)$ & $8.1(50.9)$ & $8(50.3)$ \\
\hline $\begin{array}{l}\text { Water to surface, } \mathrm{m}^{3} / \text { day } \\
\text { (STB/D) }\end{array}$ & $376.145(2370)$ & $72.9(459)$ & $75.6(476)$ \\
\hline Water injected, m/ day (STB/D) & $0(0)$ & $304(1910)$ & $301.5(1900)$ \\
\hline Surface water cut, \% & 97.7 & 90.3 \\
\hline Efficiency, \% & & 90 & 90 \\
\hline
\end{tabular}




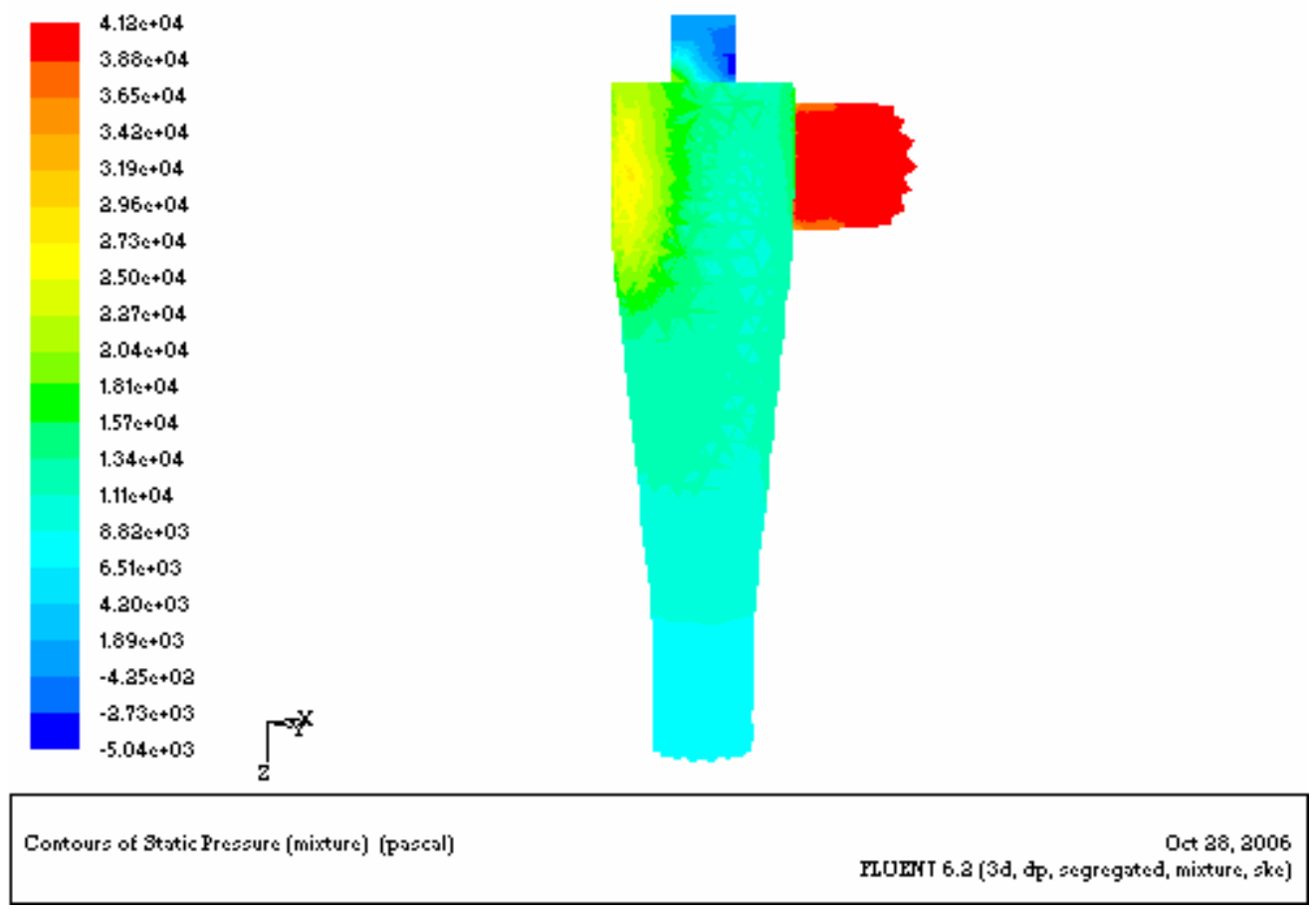

Figure 6.1: Static Pressure Profile

On the other hand, results obtained for mixture velocity profile indicates that oil has a velocity value of $4.7 \mathrm{~m} / \mathrm{s}$ compared to mixture velocity (water-oil cells) of $2.6 \mathrm{~m} / \mathrm{s}$. As shown for the profile of oil volume fraction in Figure 6.3, the fraction of oil in oil outlet increased compare to water outlet. Since the inlet chamber and reducing section have encountered more turbulence and higher tangential acceleration, oil was forced into the overflow outlet.

There are no standard procedures or available equations to set the value of back-pressure for the oil outlet. The balance between back pressure and static oil outlet pressure was one of the important criteria for oil-water separation. The pressure difference that can force oil into overflow will be an acceptable value.

As shown in Table 11, water cut was reduced from $97.7 \%$ to $90.3 \%$ in this run, compared to $90 \%$ of field study data. Surface oil content was increased from $2.3 \%$ to $9.5 \%$ while more than $78 \%$ of the total produced water was injected into the formation with the hydro-cyclone efficiency calculated as $90 \%$. 


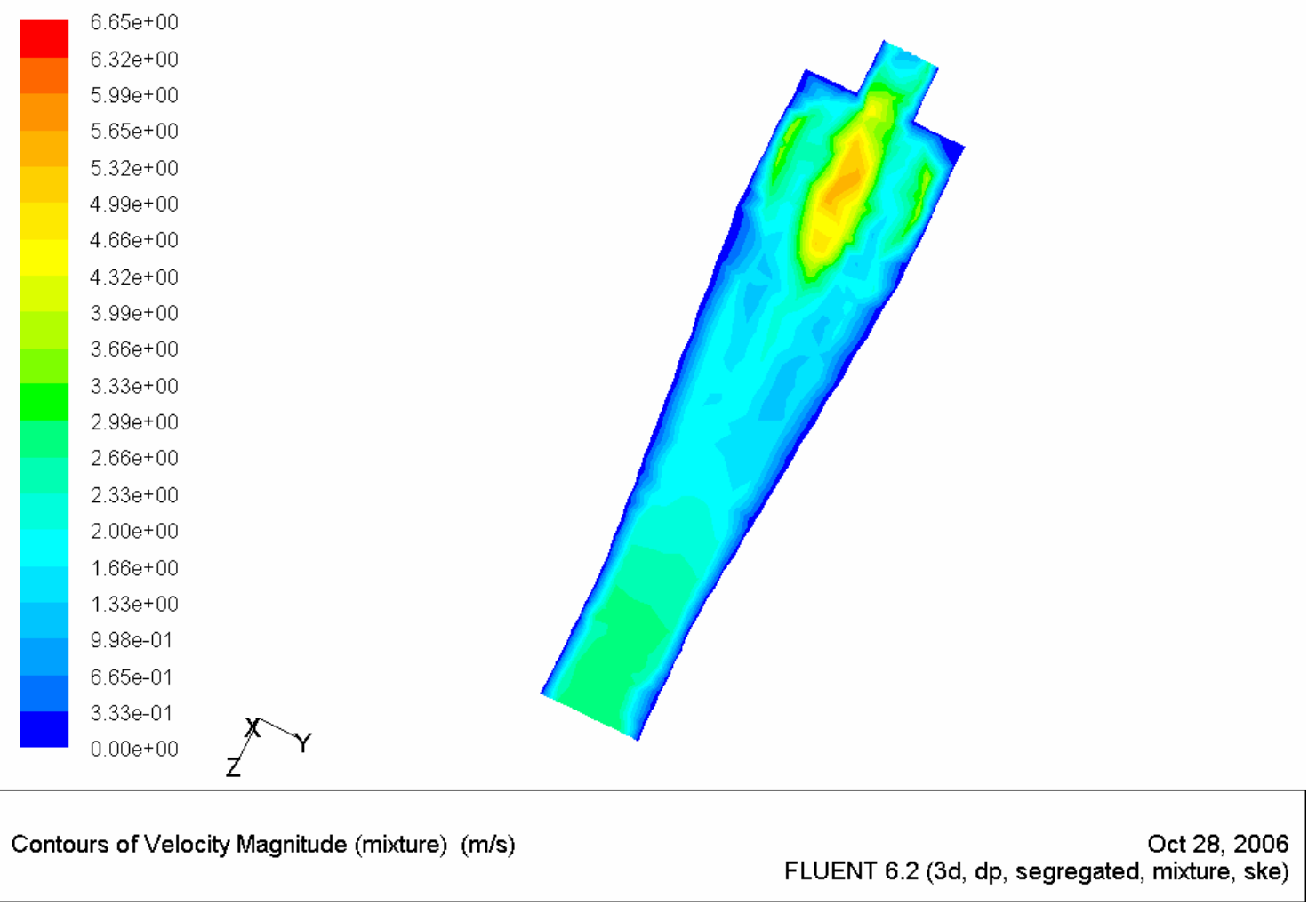

Figure 6.2: Velocity profile in cyclone (iso-surface)
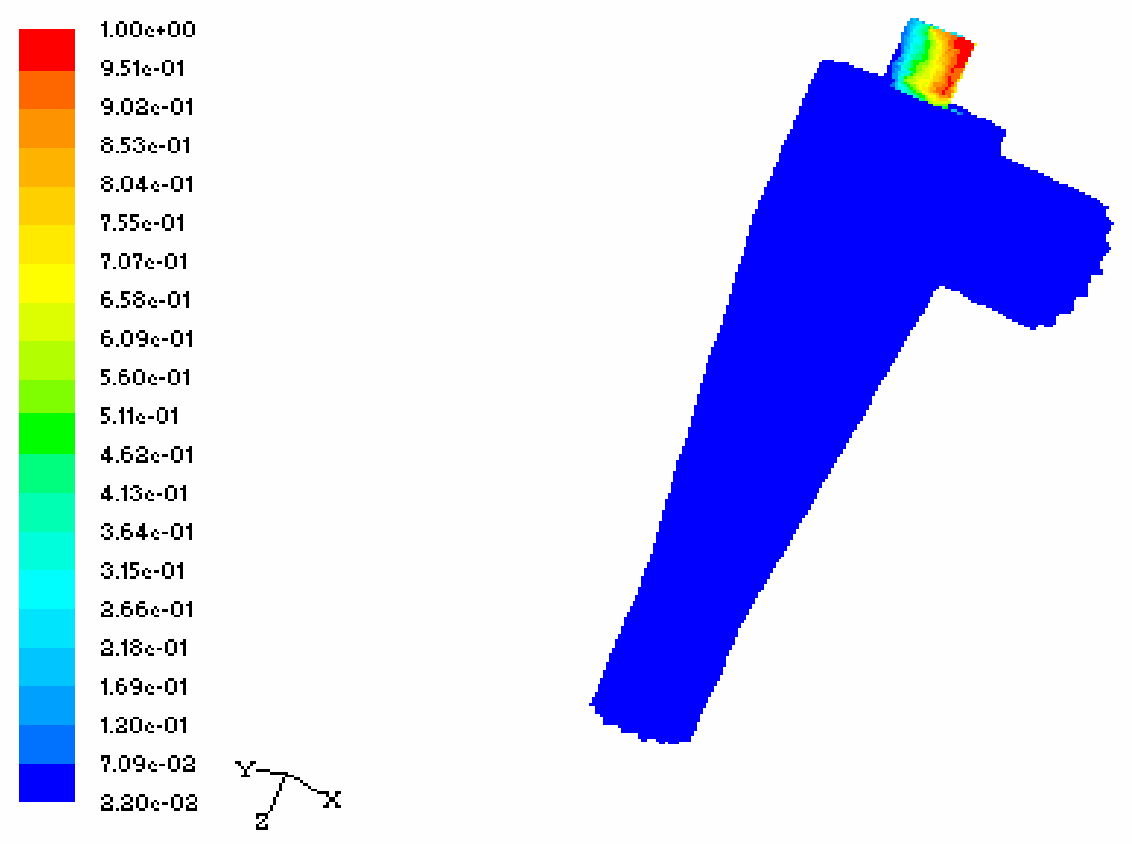

Contour $s$ of Volume traction (oil)

Scp 18, 3006

FLUसrT 6.8 [3d, dp, segregated, mixture, ske)

Figure 6.3: Profile of oil volume fraction 


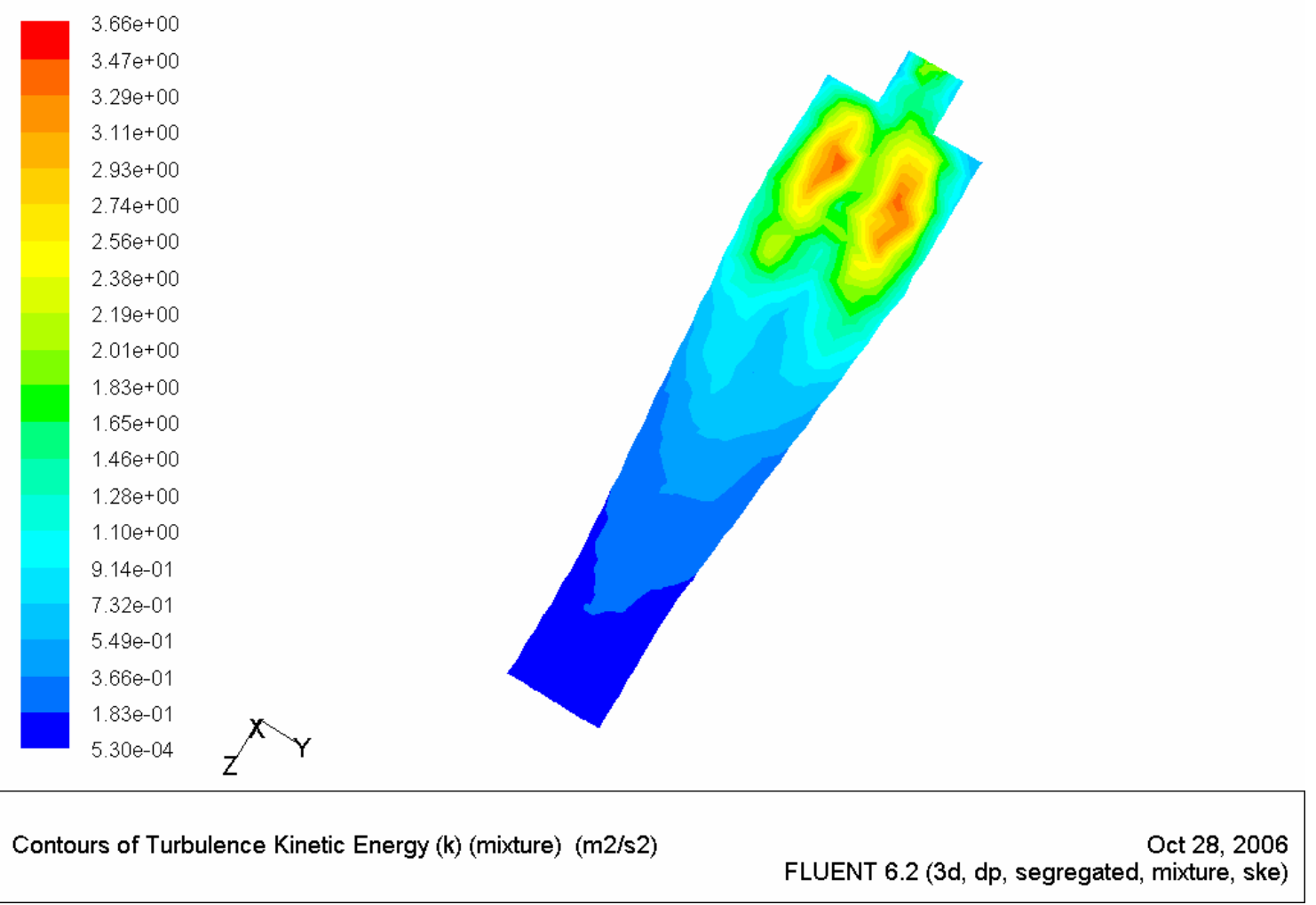

Figure 6.4: Turbulence profile (Iso surface)

\subsection{PARAMETRIC STUDY}

The aim of these runs was to investigate the efficiency of liquid-liquid hydro-cyclones for oil-water separation in down-hole conditions. In this regard, the effects of fluid properties, flow rates, inlet configurations and operational parameters on the efficiency of oil water separation processes are studied. Four different API oil gravity values of 15, 20, 30 , and 40 were used at a constant temperature of $113^{\circ} \mathrm{F}$. The well flow rates used for this study ranged between $380 \mathrm{~m}^{3} /$ day and $135 \mathrm{~m}^{3} /$ day. Two different DOWS configurations are used to determine the efficiency of the separation process. Plots are prepared for comparing the results for different fluid properties and operating conditions.

\subsection{EFFECT OF OIL PROPERTIES AND FLOW RATE}

The fluid properties studied are viscosity and density of produced oil. The DOWS model used in the verification runs was selected for the study of density and flow rate. The 
initial runs were conducted with $15^{\circ}$ API and $30^{\circ}$ API oil using $385 \mathrm{~m}^{3} /$ day $(2420$ $\mathrm{STB} / \mathrm{D})$ flow rate. The results are shown in Table 12.

As shown in Table 12, similar efficiency values were obtained for both oil samples. In the case of $30^{\circ}$ API oil, water produced to the surface was $75.6 \mathrm{~m}^{3} /$ day and injected water to the formation was $301.5 \mathrm{~m}^{3} /$ day, representing about $80 \%$ of total water. In the case of $15^{0}$ API, the water produced to the surface was $87 \mathrm{~m}^{3} /$ day, and $290 \mathrm{~m}^{3} /$ day of water was injected to the formation comprising about $77 \%$ of total water. Produced oil percentage at the surface dropped from $9.5 \%$ to $8.4 \%$ for $30^{\circ}$ API oil when compared to $15^{0}$ API oil. Pressures of oil and water outlets were major driving forces of the separation. In both cases the same values were used for both outlets.

Table 12: Effect of oil density in oil-water separation with DOWS at WOR value of 97.7

\begin{tabular}{|l|c|c|}
\hline${ }^{\mathbf{0}}$ API & $\mathbf{1 5}$ & $\mathbf{3 0}$ \\
\hline Gross rate, $\mathrm{m}^{3} /$ day (STB/D) & $385(\mathbf{2 4 2 0})$ & $385(\mathbf{2 4 2 0})$ \\
\hline Oil to surface, $\mathrm{m}^{3} /$ day (STB/D) & $8(\mathbf{5 0 . 3})$ & $8(\mathbf{5 0 . 3})$ \\
\hline Water to surface, $\mathrm{m}^{3}$ / day (STB/D) & $87(\mathbf{5 4 7})$ & $75.6(\mathbf{4 7 6})$ \\
\hline Water injected, $\mathrm{m}^{3} /$ day (STB/D) & $290(\mathbf{1 8 2 0})$ & $301.5(\mathbf{1 9 0 0})$ \\
\hline Surface water cut, \% & $\mathbf{9 1 . 6}$ & $\mathbf{9 0 . 3}$ \\
\hline Efficiency, $\%$ & $\mathbf{9 0}$ & $\mathbf{9 0}$ \\
\hline
\end{tabular}

Figures 6.5 to 6.9 present the effect of cyclone efficiency and its relationship to the flow rate and API oil gravity. There is no significant pressure difference in cyclone inlet, oil outlet and water outlet. Phases profile also indicates most of the oil fraction is at the top of the cyclone and the bottom side is almost pure water. Major turbulence occurs in the cone section as the fluid hit the wall opposite the inlet, where most of the separation takes place. It is difficult to predict the turbulence level inside the cyclone.

The flow rate of $240 \mathrm{~m}^{3} /$ day was selected in order to compare to previous run and cyclone efficiency. After several runs the difference between results for 40, 35 and 30 ${ }^{\circ} \mathrm{API}$ was less significant and the same was observed for $15^{\circ}$ and $20^{\circ} \mathrm{API}$ oils. Therefore, 
$30^{\circ} \mathrm{API}$ was selected and compared to $15^{\circ} \mathrm{API}$ gravity oil with water-oil ratio of $98 \%$. As shown in Table 13, $30^{\circ}$ API surface oil percentage was increased from $2 \%$ to $4 \%$ and total water brought to the surface was reduced to $97.9 \mathrm{~m}^{3} /$ day; yielding about $41 \%$ of the total produced water. Cyclone efficiency defined as is the ratio of total oil inlet and oil outlet, was achieved at $81.2 \%$.

For $15^{0}$ API oil gravity, surface oil percentage was increased from $2 \%$ to $2.5 \%$ and total water brought to the surface became $99.4 \mathrm{~m}^{3} /$ day, which is $42.2 \%$ of the total water and the rest of the water was injected to formation. Cyclone efficiency was $54 \%$, very low relative to results with $30^{\circ}$ API oil gravity.

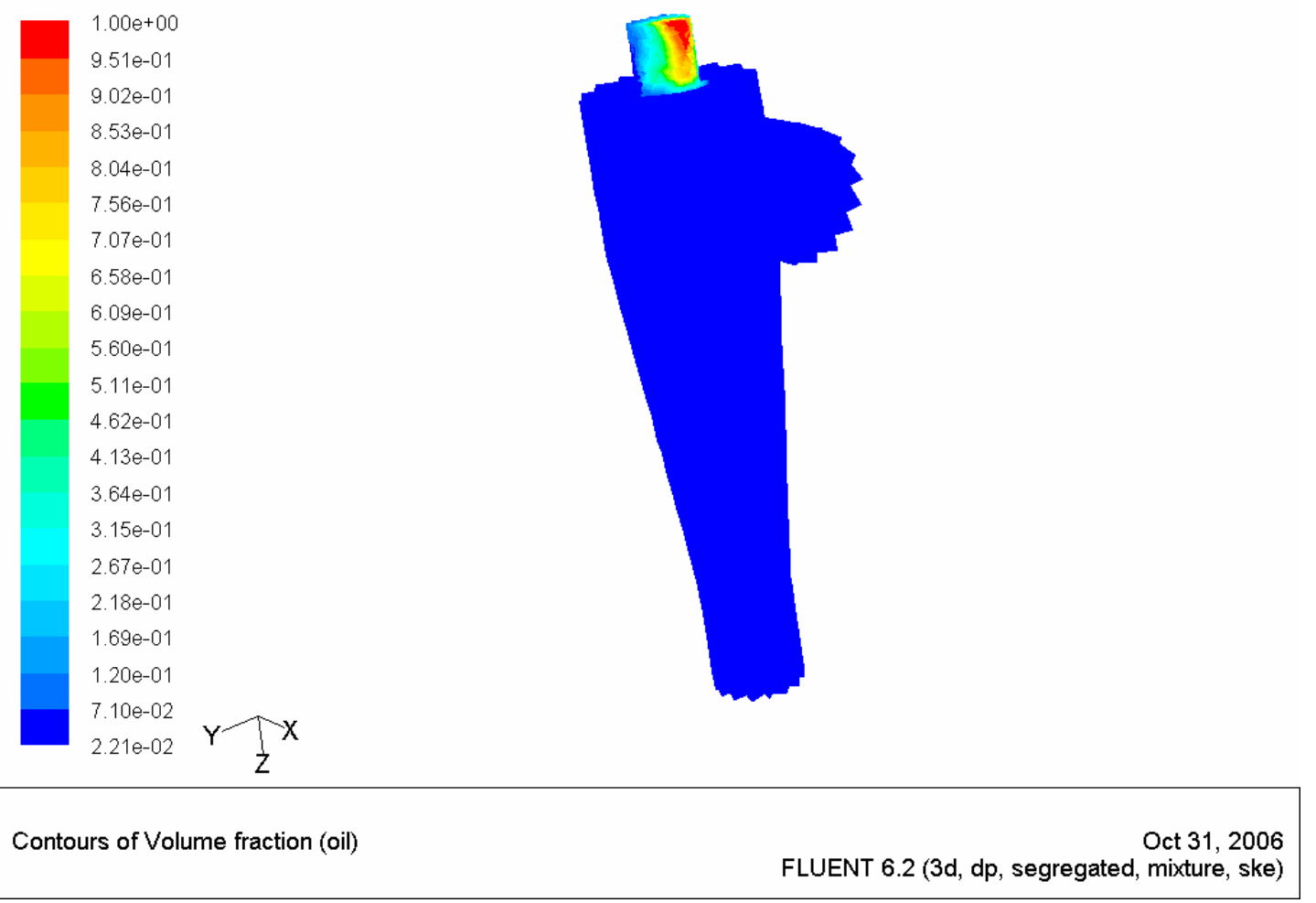

Figure 6.5: Profile of oil volume fraction $\left(15^{0} \mathrm{API}\right)$

The separation of oil from water in the swirl chamber of the cyclone is the result of forces imposed on the amount of oil in the spinning fluid, and holding time in the chamber. Lower flow rate means longer residence time and lower acceleration force. 
Table 13: Effect of oil density with DOWS at WOR of $98 \%$

\begin{tabular}{|l|c|c|c|c|}
\hline${ }^{0}$ API & $\mathbf{1 5}$ & $\mathbf{2 0}$ & $\mathbf{3 0}$ & $\mathbf{4 0}$ \\
\hline Gross rate, $\mathrm{m}^{3}$ / day(STB/D) & $240(1510)$ & $240(1510)$ & $240(1510)$ & $240(1510)$ \\
\hline Oil to surface, $\mathrm{m}^{3}$ / day(STB/D & $2.6(16.4)$ & $2.7(17)$ & $3.9(25.8)$ & $3.42(21.5)$ \\
\hline Water to surface, $\mathrm{m}^{3}$ / day(STB/D & $99.4(625)$ & $99.3(625)$ & $98.1(616)$ & $98.56(620)$ \\
\hline Water injected, $\mathrm{m}^{3}$ / day(STB/D & $138(868)$ & $138(868)$ & $138(868)$ & $138(868)$ \\
\hline Surface water cut, $\%$ & 97.4 & 97.3 & 96 & 96.6 \\
\hline Efficiency, \% & 54 & 56 & 81.2 & 71 \\
\hline
\end{tabular}

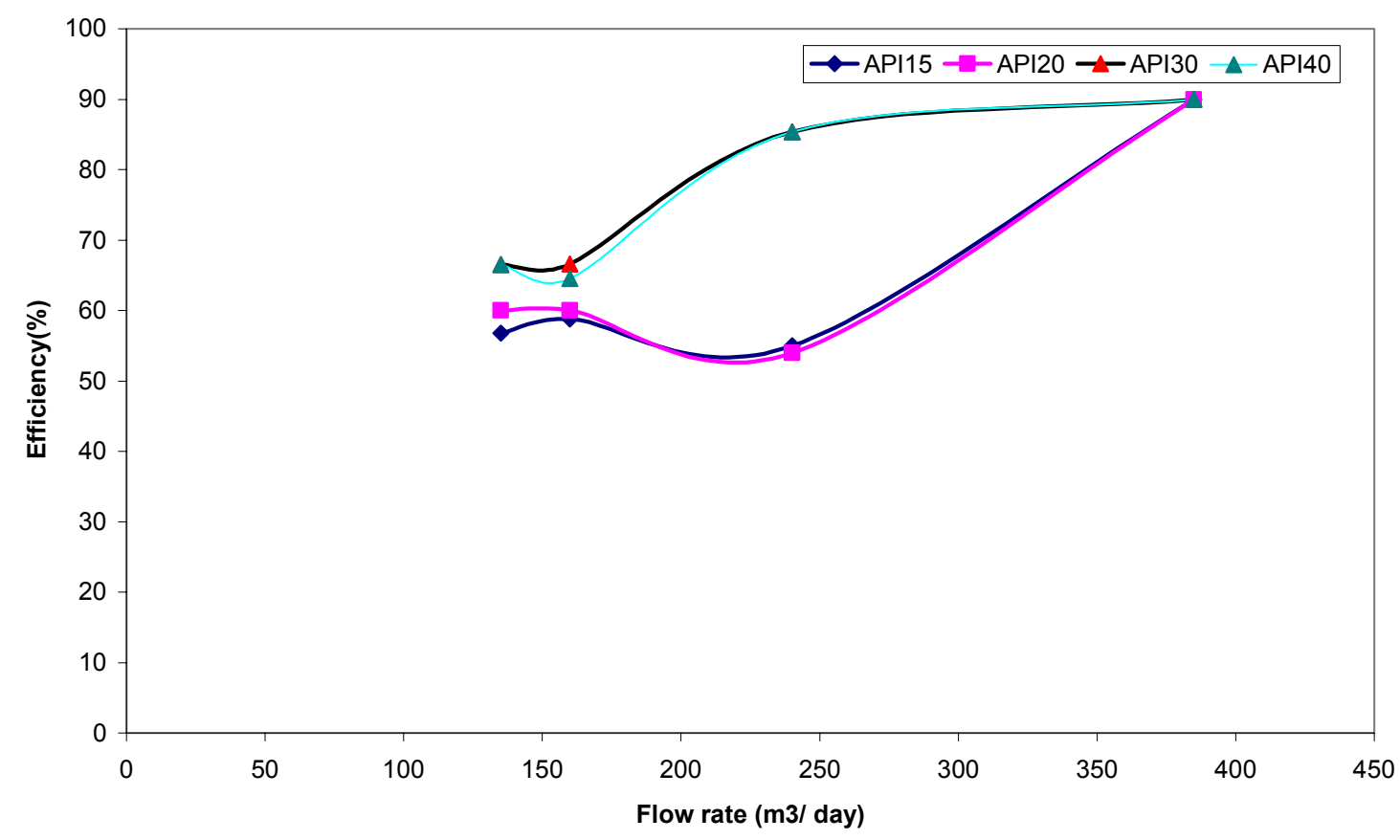

Figure6. 6: Variation of cyclone efficiency with well flow rate for four different oil densities

As presented in Tables 14 and 15 inlet flow rate of the cyclone was reduced to $160 \mathrm{~m}^{3} /$ day and $135 \mathrm{~m}^{3}$ / day with different API oil gravities and different water-oil ratios of $97 \%$ and $98 \%$. The results for flow rate of $160 \mathrm{~m}^{3} /$ day are shown in Table 14. Surface oil percent was improved slightly, from $3 \%$ to $3.1 \%$ for $40^{\circ}$ API oil; water brought to the surface was reduced to $96.9 \mathrm{~m}^{3} /$ day and $58.3 \mathrm{~m}^{3} /$ day $(37.5 \%)$ of total water was injected to the formation, and cyclone efficiency was calculated by $64.5 \%$. On the other hand, $30^{\circ}$ API surface oil percent was improved from $3 \%$ to $3.2 \%$, water brought to the surface was reduced by $40 \%$, and the cyclone efficiency was calculated as $66.6 \%$. 


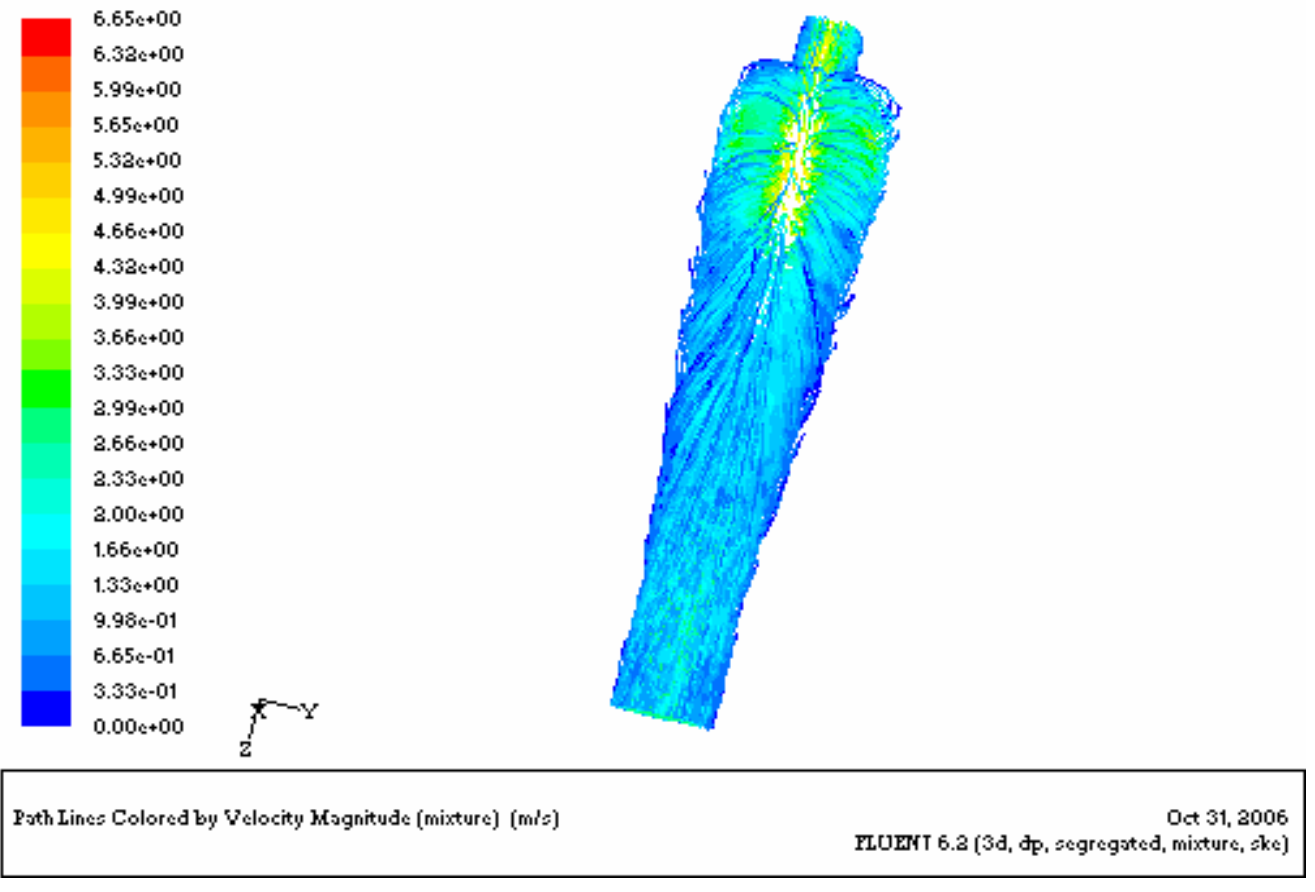

Figure 6. 7: Velocity profile

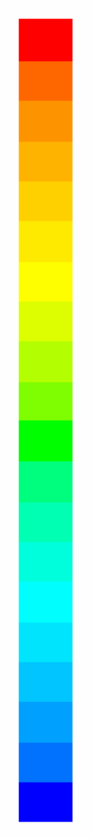
$1.00 e+00$
9.51e-01
9.02e-01
8.53e-01
8.04e-01
$7.55 \mathrm{e}-01$
7.06e-01
$6.57 \mathrm{e}-01$
$6.08 \mathrm{e}-01$
5.60e-01
5.11e-01
4.62e-01
4. $13 \mathrm{e}-01$
3. $64 \mathrm{e}-01$
3. $15 \mathrm{e}-01$
2.66e-01
2.17e-01
$1.68 \mathrm{e}-01$
$1.19 \mathrm{e}-01$
$7.02 \mathrm{e}-02$
$2.12 \mathrm{e}-02$$\sum_{Z} \mathrm{X}$

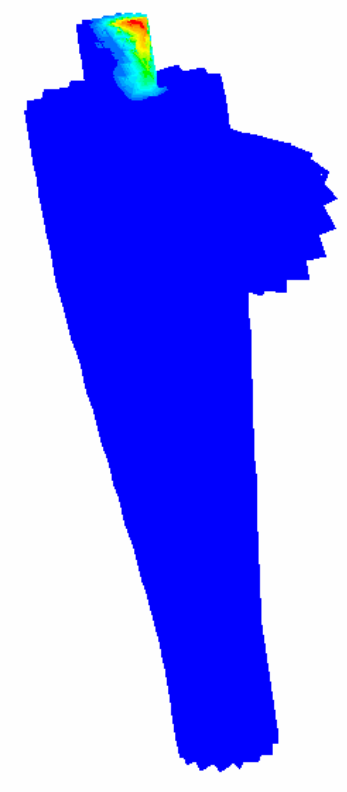

Contours of Volume fraction (oil)

Oct 31, 2006

FLUENT 6.2 (3d, dp, segregated, mixture, ske)

Figure 6.8: Profile of oil volume fraction $\left(35^{\circ} \mathrm{API}\right)$ 
For $20^{\circ}$ API oil, surface oil percent was slightly reduced from $3 \%$ to $2.8 \%$ and surface water cut remained the same, but water brought to the surface was reduced by $36.8 \%$ and the efficiency of the cyclone was lower relative to $40^{\circ}$ and $30^{\circ}$ API oil densities.

Table 14: Effect of oil density in oil-water separation with DOWS in WOR of 97\%

\begin{tabular}{|l|c|c|c|c|}
\hline${ }^{0}$ API & $\mathbf{1 5}$ & $\mathbf{2 0}$ & $\mathbf{3 0}$ & $\mathbf{4 0}$ \\
\hline Gross rate, $\mathrm{m}^{3} /$ day(STB/D) & $160(1010)$ & $160(1010)$ & $160(1010)$ & $160(1010)$ \\
\hline Oil to surface, $\mathrm{m}^{3} /$ day(STB/D) & $2.8(17.6)$ & $2.9(18.2)$ & $3.2(20.1)$ & $3.1(19.5)$ \\
\hline Water to surface $\mathrm{m}^{3} /$ day(STB/D) & $98.1(617)$ & $98(616)$ & $94.8(596)$ & $96.9(609)$ \\
\hline Water injected, $\mathrm{m}^{3} /$ day(STB/D) & $59.1(372)$ & $59.1(372)$ & $62(390)$ & $60(377)$ \\
\hline Surface water cut, \% & $\mathbf{9 7 . 2}$ & $\mathbf{9 7}$ & $\mathbf{9 6}$ & $\mathbf{9 7}$ \\
\hline Efficiency, \% & $\mathbf{5 8 . 8}$ & $\mathbf{6 0}$ & $\mathbf{6 6 . 6}$ & $\mathbf{6 4 . 5}$ \\
\hline
\end{tabular}

Similarly, $135 \mathrm{~m}^{3} / \mathrm{d}$ flow rate was used and the result (Table 15.) shows that the efficiency of the cyclone is very low at low flow rate for heavier oil gravity $\left(20^{\circ} \mathrm{API}\right)$. Separation became very difficult because of high residence time and lower acceleration force. Compared with higher flow rates (Tables 12 and 13), better separation and high efficiency rate are the result of higher acceleration force and lower residence time.

Table 15: Effect of oil density in oil-water separation with DOWS in WOR of 96\%

\begin{tabular}{|l|c|c|c|c|}
\hline${ }^{\mathbf{0}}$ API & $\mathbf{1 5}$ & $\mathbf{2 0}$ & $\mathbf{3 0}$ & $\mathbf{4 0}$ \\
\hline Gross rate, $\mathrm{m}^{3} /$ day(STB/D) & $135(849)$ & $135(849)$ & $135(849)$ & $135(849)$ \\
\hline Oil to surface, $\mathrm{m}^{3} /$ day(STB/D) & $3.069(19.3)$ & $3.2(20.1)$ & $3.595(22.6)$ & $3.6(22.6)$ \\
\hline Water to surface, $\mathrm{m}^{3} /$ day(STB/D) & $77.93(490)$ & $77.8(489)$ & $86.2(542)$ & $85.4(537)$ \\
\hline Water injected, $\mathrm{m}^{3} /$ day(STB/D) & $54(340)$ & $54(340)$ & $45.2(284)$ & $46(289)$ \\
\hline Surface water cut,\% & $\mathbf{9 6 . 2}$ & $\mathbf{9 6}$ & $\mathbf{9 5 . 9}$ & $\mathbf{9 5 . 9}$ \\
\hline Efficiency,\% & $\mathbf{5 6 . 8}$ & $\mathbf{6 0}$ & $\mathbf{6 6 . 5}$ & $\mathbf{6 6 . 5}$ \\
\hline
\end{tabular}




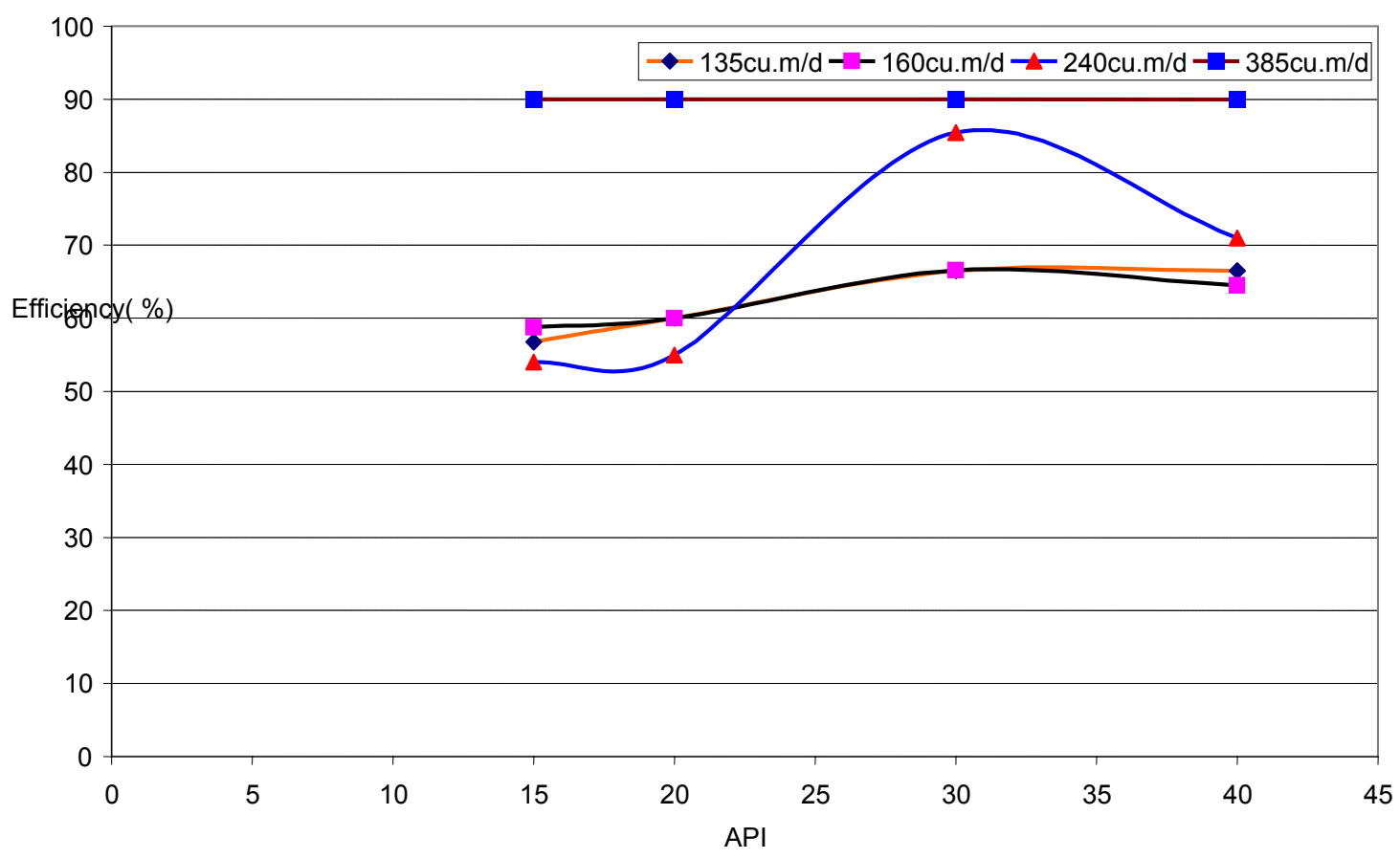

Figure 6.9: Variation of cyclone efficiency with oil density for four different well flow rates

\subsection{THE EFFECT OF INLET CONFIGURATION}

One of the important parameters of the LLHC is the inlet configuration. The main goal is to inject the fluid with high tangential velocity, avoiding the rupture of the droplets.

Post-processing software was used to create a showing similar shape and geometry of LLHC with a but modified inlet diameter (reduced from two inches to one inch). The cyclone was under the same conditions as previous runs in order to understand maximum and minimum operating conditions of the cyclone. The results are shown in Tables 16 and 17.

Table 16: Effect of reduced inlet in oil-water separation with WOR of $98 \%$

\begin{tabular}{|l|c|c|c|}
\hline${ }^{\mathbf{0}}$ API & $\mathbf{1 5}$ & $\mathbf{3 0}$ & $\mathbf{4 0}$ \\
\hline Gross rate, $\mathrm{m}^{3}$ / day(STB/D) & $240(1540)$ & $240(1540)$ & $240(1540)$ \\
\hline Oil to surface, $\mathrm{m}^{3} /$ day(STB/D) & $4.19(26.354)$ & $4.7(29.56)$ & $4.3(27.046)$ \\
\hline Water to surface, $\mathrm{m}^{3}$ / day(STB/D) & $117,8(741)$ & $117.3(737.8)$ & $111.7(702.57)$ \\
\hline Water injected, $\mathrm{m}^{3}$ / day(STB/D) & $118(742.2)$ & $118(742.2)$ & $124(780)$ \\
\hline Surface water cut $\mathbf{\%}$ & $\mathbf{9 6 . 5}$ & $\mathbf{9 6}$ & $\mathbf{9 6 . 2}$ \\
\hline Efficiency $\mathbf{\%}$ & $\mathbf{7 6}$ & $\mathbf{8 5}$ & $\mathbf{7 7 . 8}$ \\
\hline
\end{tabular}


Table 17: Effect of reduced inlet in oil-water separation with WOR of $97 \%$

\begin{tabular}{|l|c|c|c|}
\hline${ }^{\mathbf{0}}$ API & $\mathbf{2 0}$ & $\mathbf{3 0}$ & $\mathbf{4 0}$ \\
\hline Gross rate, $\mathrm{m}^{3} /$ day(STB/D) & $160(1010)$ & $160(1010)$ & $160(1010)$ \\
\hline Oil to surface, $\mathrm{m}^{3} /$ day(STB/D) & $3.8(24)$ & $3.85(24.2157)$ & 4 \\
\hline Water to surface, $\mathrm{m}^{3} /$ day(STB/D) & $113.2(712)$ & $113.15(711.7)$ & $113(710.748)$ \\
\hline Water injected, $\mathrm{m}^{3} /$ day(STB/D) & $43(270.46)$ & $43(270.46)$ & $43(270.46)$ \\
\hline Surface water cut, \% & $\mathbf{9 6 . 7}$ & $\mathbf{9 6 . 7}$ & $\mathbf{9 6 . 5}$ \\
\hline Efficiency, $\%$ & $\mathbf{7 9}$ & $\mathbf{8 0}$ & $\mathbf{8 3 . 3}$ \\
\hline
\end{tabular}

To summarize Table $16\left(240 \mathrm{~m}^{3} /\right.$ day $)$, over half of the produced water was injected to the formation while the other half was brought to the surface. Surface oil percent was improved from $2 \%$ to $3.5 \%$. In the previous run with large inlet diameter surface oil percent was increase from $2 \%$ to $4 \%$ and total water brought to the surface was reduced to $97 \mathrm{~m}^{3} /$ day, or $41 \%$. Figure 6.10 shows the efficiency of the cyclone with different inlet diameter or higher inlet-velocity for two different well flow rates.

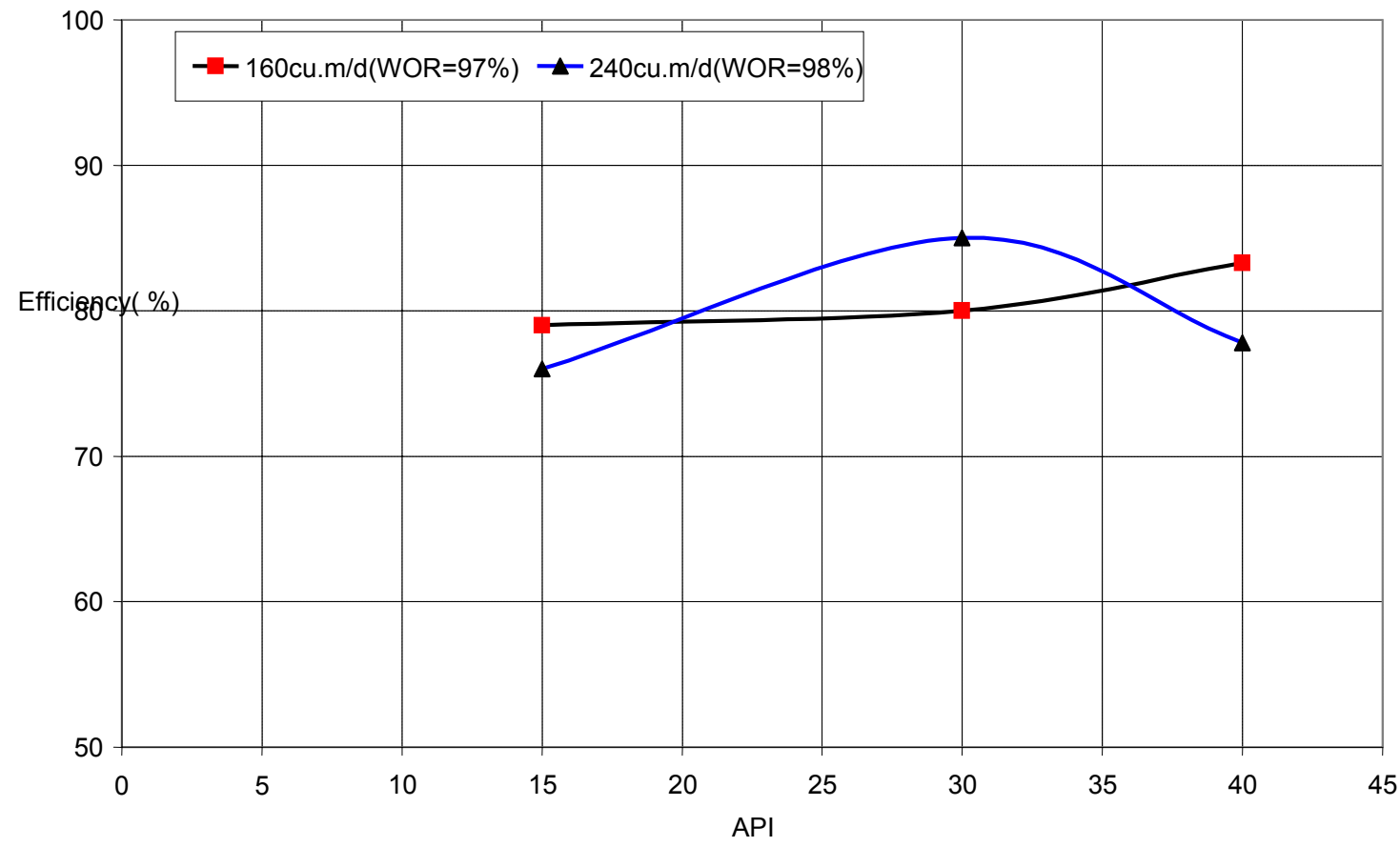

Figure 6.10: Variation of cyclone efficiency with oil density for two different flow rates with smaller inlet size 


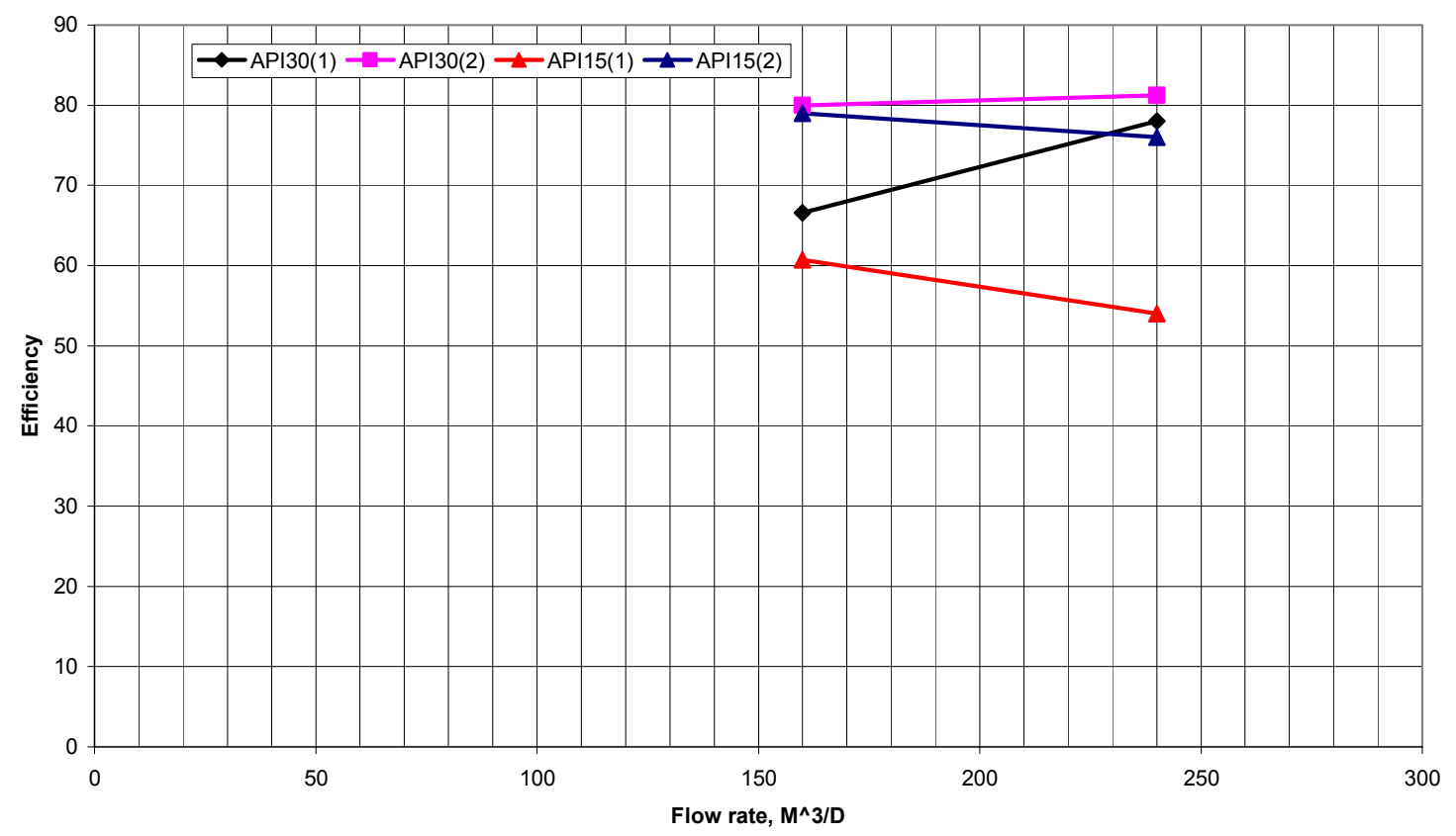

Figure 6.11 Variation of cyclone efficiency with well flow rates for two different inlet design

Figure 6.11 shows the results obtained for two different cyclone designs based on inlet diameters. Two separate oil densities were used with each cyclone design under two different well flow rates. The efficiency of cyclones shows an increasing trend with increase in flow rates when $30^{\circ}$ API oil is in the mixture. Whereas, the efficiency of both cyclones decreases with increase in flow rate for $15^{\circ}$ API oil-water mixtures. 


\section{CHAPTER VII: CONCLUSIONS AND RECOMMENDATIONS}

\subsection{CONCLUSIONS}

In this research, the effect of fluid properties and operational parameters are studied for down-hole hydro-cyclone separation (DOWS). Two different physical models are used to represent DOWS. The fluid flow and the performance were modeled with the Computational Fluid Dynamics program available at WVU. The work consists of four different oil densities of $15,20,30$ and $40^{\circ}$ API and four different well production rates of $385,240,160$ and $135 \mathrm{~m}^{3} / \mathrm{d}$. Based on the result, the following conclusions are presented:

- The CFD model was successfully used to represent down-hole cyclone separators.

- Hydro-cyclone separation efficiency increases with increase in oil API density. This increase was more pronounced at lower flow rates. At high rates the efficiency values were the same for all oil density values.

- For runs conducted at the wellbore flow rate of $385 \mathrm{~m}^{3} / \mathrm{d}$, the surface water cut percentage values were $90.3 \%$ and $91.6 \%$ for $30^{\circ}$ and $15^{\circ}$ API oil, respectively.

- Surface water cut values were $90.3 \%$ and $91.6 \%$ for $30^{\circ}$ and $15^{\circ}$ API oil, respectively, for the wellbore flow rate of $240 \mathrm{~m}^{3} / \mathrm{d}$.

- At the wellbore flow rates of $160 \mathrm{~m}^{3} / \mathrm{d}$, the surface water cut percentages were 97, 96 and 97 for $20^{\circ}, 30^{\circ}$ and $40^{\circ}$ API oil density, respectively.

\subsection{RECOMMENDATIONS}

- Effect of different cyclone geometry on efficiency of oil separation needs to be studied.

- Separation efficiency of more than one cyclone installed in series needs to be studied.

- Further research is needed to determine the optimum pressure setting of downhole hydro-cyclone . 


\section{REFERENCES}

1. Flow Modeling Solution for Oil and Gas Industries "http://www.fluent.com/solution/brochures/oigas.pdf"

2. Bradley, D., The Hydro-cyclone, edited by P.V. Danckwerts, Pergamon Press, Oxford, 1965

3. Coleman, D.A., Thew, M.T., "The concept of hydro-cyclones for separating light dispersions and comparison of field data with laboratory work ", paper F2, 2 nd Int. Conf. on Hydro-cyclones, Sep. 1984

4. A. E. Blanco and D. R. Davies "Technical \& Economic Application Guidelines for Downhole Oil-Water Separation Technology", SPE Paper 67182 Production and operation Symposium Oklahoma 24-27 March, 2001

5. T. Kjos, A.S.,S. Sangesland, J.F. Michelet and J. Kleppe:Down-Hole Water-Oil Separation and Water Reinjection through Well Branches"Presented at the 1995 SPE Annual Meeting held in Dallas

6. Carlos Gomez, Juan Caldentey, Shoubo Wang, Luis Gomez, Ram Mohan and Ovadia Shoham, "Oil-Water Separation in Liquid-Liquid Hydro-cyclones (LLHC) Experiment and Modeling" SPE Paper 71538, presented Annual Conf. 30 Sept. 2001

7. Meldrum, N., "Hydro-cyclone: A solution to produced water treatment", $19^{\text {th }}$ Annual OTC, Houston Texas, April 1987

8. Pericleous, K. A., Rhodes, N., "A mathematical model for predicting the flow field in a hydro-cyclone classifier", Paper B1, $2^{\text {nd }}$ Int. Conf. on Hydro-cyclones, Sept. 1984

9. C. Chapuis, SPE, and Y. Lacourie, and D. Lançois, ELF Exploration Production "Testing of Down -Hole Oil/Water Separation system in Lacq Superieur Field, France" Paper SPE 54748 presented SPE Formation damage, The Netherlands, 31 May-June 1999

10. O.O. Ogunsina, SPE, and M.L. Wiggins, SPE, U. of Oklahoma "A Review of Downhole Separation Technology" SPE Paper of Production and operations presented Oklahoma, 17-19 April 2005

11. John A Veil and John J. Quinn, Argonne Laboratory" Down-Hole Separation Technology Performance: Relation-ship to Geologic Condition" Presented for at 
2005 SPE/EPA/DOE Exploration and Production Environmental Conference held in Galveston, TX, USA 7-9 March 2005

12. J.L. Scaramuzza, Repsol-YPF; H. Fischetti, Repsol-YPF; L. Strappa, RepsolYPF and S. Figliuolo, Repsol-YPF “ Downhole Oil/Water Separation System Field Pilot-Secondary Recovery Application Project” SPE Paper 69408 presented Latin America and Caribbean Petroleum Engineering Conf. Argentina, 25-28 March 2001

13. John E Sutton, Process design consideration for heavy crude, Chem. Eng, May 1997

14. FLUENT 6.2 DOCUMENTATION [http/: fluent.inc \fluent6.2.16 \help \index.htm]

15. John E Sutton, Process design consideration for heavy crude, May $19974^{\text {th }}$ annual event of Production Separation System Forum

16. P.D Martin and S.Hartland, Design simple gravity settlers, for the coalescence of liquid-liquid dispersion October 1984

17. William B Hooper and Louis J. Jacobs, Handbook of separation technique for chemical engineers, 1979

18. ALLAK. A.M.A and JEFFREYS. G.V. (1974. A.I.CH.E.J. 20(3)564

19. BARNEVA. E. and MIZRAHI. J (1974). Trans. I Chem. E. (Lond), 53,61 